NBSIR 82-2489

\title{
Strategies for Energy
} Conservation in Small Office Buildings

\section{U.S. DEPARTMENT OF COMMERCE}

National Bureau of Standards

National Engineering Laboratory

Center for Building Technology

Building Equipment Division

Washington, DC 20234

June 1982

Prepared for

Office of Buildings Energy Research and Development iffice of Conservation and Renewable Energy .S. Department of Energy 



\section{STRATEGIES FOR ENERGY CONSERVATION IN SMALL OFFICE BUILDINGS}

Walter H. Parken

James Y. Kao

George E. Kelly

U.S. DEPARTMENT OF COMMERCE

National Bureau of Standards

National Engineering Laboratory

Center for Building Technology

Building Equipment Division

Washington, DC 20234

June 1982

\section{Prepared for}

Office of Buildings Energy Research

and Development

Office of Conservation and Renewable Energy

U.S. Department of Energy

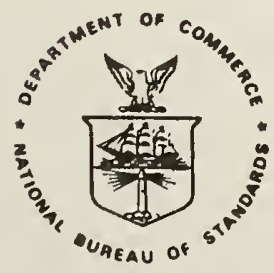

U.S. DEPARTMENT OF COMMERCE, Malcolm Baldrige, Secretary NATIONAL BUREAU OF STANDARDS, Emest Ambler, Director 



\section{ABSTRACT}

A comparative analysis is made of the thermal performance of a small office building using various HVAC systems and commonly employed strategies. The conparisons are made for seven geographical locations representing vide climatic variations within the continental United States.

Results were obtained for fan, space heating hot water, and chil.led water enerrv consumption through hour-by-hour simulations using the BIAST comnuter progran. A small office building model was used in the simulations along with several HVAC systems; a constant volume reheat unit (servins the entire builing), dual constant volume reheat units (serving separate zones of the huilting), and a variable air volume reheat unit. The strategies investioated included sunply air temperature reset (constant, zone-controlled, and outdoor air-controlled), economy cycles (temperature and enthalpy), continuous conditioning versus conditioning only during occupied hours, changes in reheat set point temperature, and changes in minimum variable air volume ratio.

For comparahle control strategies, the variable-air volume terminal reheat system exhihited the least energy consumption for chilled water, hot water and circulating fan. The system incorporating two independently-operating constant volume terminal reheat units ranked second in energy consumption while the single constant volume terminal reheat unit ranked last. Changes in thermal performance resulting from implementing one strategy in place of or in combination with another were found to vary significantly by climate and the type of HVAC system employed.

Key words: Building control strategies; building energy conservation; building thermal performance; HVAC. 
This report is one of a series documenting NBS research and analysis efforts in developing energy and cost data to support the Department of Energy/National Bureau of Standards Building Energy Conservation Criteria Program. The work reported in this document was performed under the Energy Analysis of Control Strategies project; a part of the Controls Program element managed by Brookhaven National Laboratory for DoE. The NBS effort was supporter by DoE/NBS Task Order A008-BCS under Interagency Agreement No. EA77A 01-6010. 
ABSTRACT ...............................................

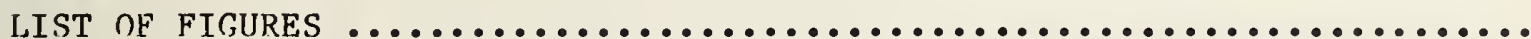

LIST OF TARIJES

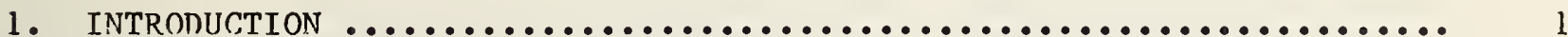

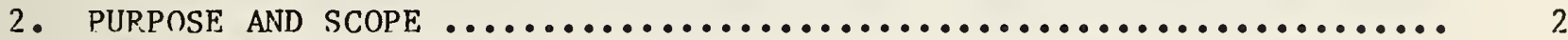

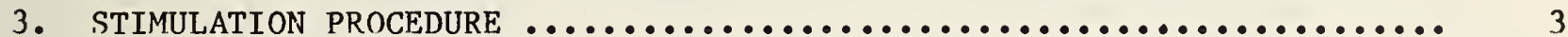

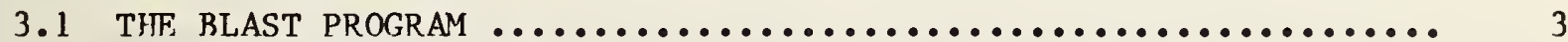

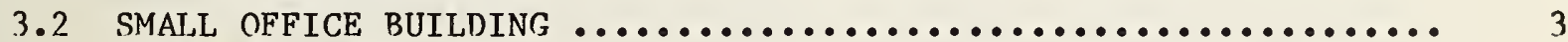

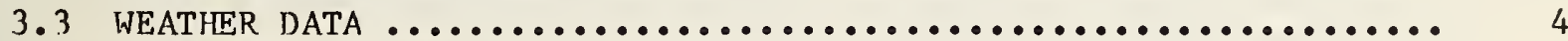

4. SIMULATION OF HVAC SYSTEMS AND STRATFGIES ...................

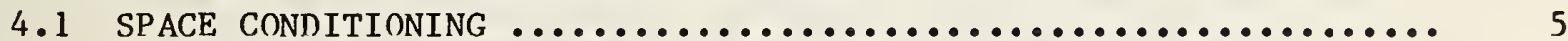

4.2 CONSTANT VOLIMME TERMINAL REHEAT SYSTEM SERVING THE ENTIRE

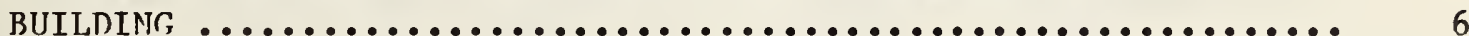
4.2 .1 CV System strategies ..........................

4.3 SYSTEM INCORPORATING TWO CONSTANT VOLUME TERMINAL REHEAT

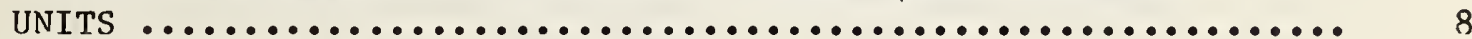

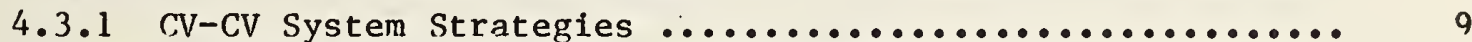

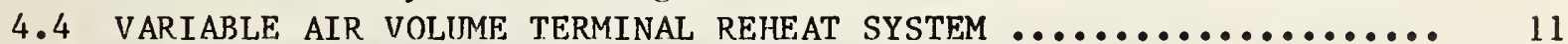

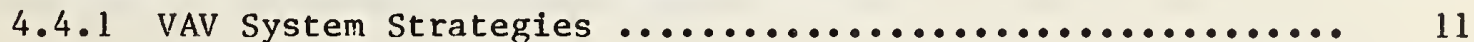

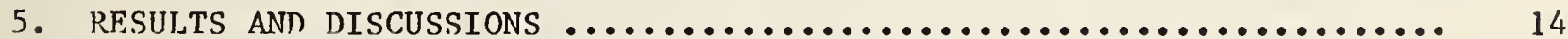

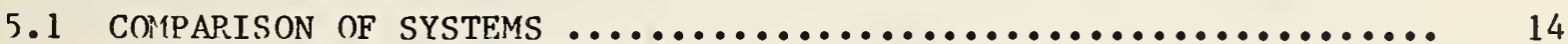

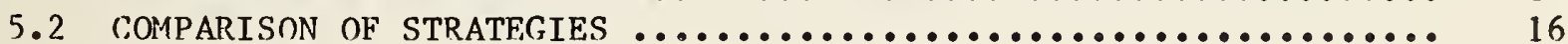

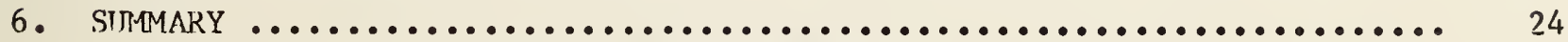

ń.l FIVALIIATION OF SYSTFMS AND STRATEGIES $\ldots \ldots \ldots \ldots \ldots$

APPFIIIIX A: RF.SULTS FROM SIMULATIONS OF ADDITTONAJ STRATEGIES ........ A-1 


\section{LIST OF FIGURES}

Figure

Page

1. Small office building model .............................. 29

2. Internal heat gain schedules $\ldots \ldots \ldots \ldots \ldots \ldots \ldots \ldots \ldots \ldots \ldots \ldots \ldots \ldots \ldots . . \ldots \ldots$

3. Annual heating and cooling energy consumption of three HVAC systems utilizing the base case strategy (A-1) for a small office building

4. Comparative annual heating and cooling energy consumption for a VAV system using the base case strategy with CV and CV-CV system utilizing their representative best case strategies .............

5. Percent savings in chilled water and percent increases in hot water energy consumption for three HVAC systems using enthalpy economy cycle

6. Percent savings in chilled water and percent increases in hot water energy consumption for three HVAC systems using temperature economy cycle

7. Chilled water and hot water energy savings achieved for strategies employing zone-controlled cold deck as compared to a fixed cold deck temperature 
Table

Pagre

1. Climatological Data for Seven Cities ..................... $3 \hbar$

2. Comparative Annual Energy Consumption of Three HVAC Systems and Selected Strategies for a Small office Building: Lake Charles ....

3. Comparative Annual Energy Consumption of Three HVAC Systems and Selected Strategies for a Small office Building: Nashville .......

4. Comparative Annual Energy Consumption of Three HVAC Systems and Selected Strategies for a Small office Building: Washington DC,...

5. Comparative Annual Energy Consumption of Three HVAC Systems and Selected Strategies for a Small office Building: Dodge City ......

6. Comparative Annual Energy Consumption of Three HVAC Systems and Selected Strategies for a Small Office Building: Madison ........

7. Comparative Annual Energy Consumption of Three HVAC Systems and Selected Strategies for a Small office Building: Seattle ........

8. Comparative Annual Energy Consumption of Three HVAC Systems and Selected Strategies for a Small office Building: Santa Maria .....

A-1. Comparison of Energy Consumption for VAV Systems with Minimum Air

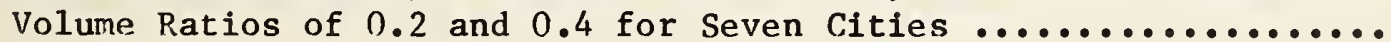





\section{INTRONUCTION}

Approximatrly 40 percent of the energy used annually in the United States is consumed in buildings. Reduced building energy consumption can therefore have a large impact in both public and private sectors and permit reallocation of scarce resources. The necessity for conserving energy has been recognized and attempts to promote conservation have taken many forms, such as federallymandated emergency building temperature restrictions, proposed new standards for energy conservation in new buildings, and development of more energyefficient heating and cooling equipment.

Recently, more energy efficient architectural designs have been employed in new commercial buildings. Examples include reduced glass area, utilizing reflective and insulating glass, and reorienting glass surfaces to take advantage of natural daylighting and reducing summer solar transmission heat gain. The energy savings due to efficient building shell design, however, can be negated by high energy consumption due to improper selection, sizing, and operation of HVAC, equipment.

Computerized energy management and control systems (EMCS) are also gaining popularity as an effective means to reduce building energy usage. Achieving energy savings with these systems requires a thorough knowledge of HVAC equipment performance and the utilization of effective strategies for controlling the building environment. The proper selection of HVAC systems and utilization of effective strategies plays a key role in reducing heating and cooling costs in new as well as existing buildings. 


\section{PURPOSE AND SCOPE}

This is one of several reports intended to document the energy savings potential of HVAC systems and strategies that can be employed in public buildings. The subject of this report is the energy-savings potential of HVAC systems and strategies employed in typical small office buildings.

The report is intended to be used as a general guide for designers, consultants, and building owers or operators desiring to retrofit or install new HVAC systems in small office buildings. This information can assist in determining from the many possible combinations of systems and strategies those which are energyefficient and cost-effective. Once the choices of systems and strategies have been narrowed, a more detailed analysis can be made incorporating the unique aspects of a particular building and its intended use. In addition, it is hoped that this report will create an awareness of the sensitivity of energy cost to type of HVAC, system installed and how it is operated.

\section{Scope}

In evaluating the thermal performance of selected HVAC systems, simulations were made using the Building Loads Analysis System Thermodynamics (BLAST) ${ }^{1}$ computer program. This report focuses on three types of terminal reheat systems: a variable-air volume (VAV) system, two constant volume terminal reheat units ( $C V-C V)$ serving separate zones of the building, and a single constant volume (CV) system. These systems were selected since they are commonly employed in new and existing small office buildings and would be expected to show significant performance changes depending on climate and type of control strategy employed. Induction units were not investigated due to the limitations in the computer program selected for the simulations.

A small office building model was utilized to simulate the expected heating and cooling loads imposed on the various selected systems and strategies. Since the building loads as well as system performance is dependent on climate, results were obtained from weather data for seven cities.

Due to the impracticality of examining the numerous heating and cooling systems available and their performance in a wide variety of structures, it is clear that the present results should not be applied directly to specific situations, but used as general guidelines. These guidelines can aid in retrofitting and installing new equipment by reducing the many options from which to choose.

The dynamics of controls can also have a significant impact on the total building energy consumption. In the present study, the dynamic minute-byminute interaction of air handling system controls on building zone loads and zone air temperature was not investigated.

1 Douglas C. Hittle, The Building Loads Analysis System Thermodynamics (BLAST) Program: Report Number CERI-TR-F-153, Construction Fngineering Research Laboratory, June 1979. 


\section{SIMUI,ATION PROCF.DURE}

\subsection{THE RIJAST PROGPAM}

The Building Loads Analysis System Thermodynamics (BLAST) program was used to predict the heating and cooling loads of a small office building and the annual energy consumption of selected systems and strategies. The progran is divided into several distinct subprograms of which the building loads and air handling system subprograms were used in this study. The building loads subprogram requires a wide variety of input data including hourly weather data, thermophysical properties of the various surfaces as well as hourly internal heat gain schedules generated by occupants, lights and electrical equipment. The building is subdivided into thermally uniform zones and the hourly heating and cooling loads and air temperatures in each zone are calculated. In order for the calculation to proceed, hourly zone air temperature control profiles must be specified. The zone air temperature control profiles are used to simulate actual control operation within a building zone. The type of controls and the air handling system capability to maintain desired conditions within the zone must be anticipated by the user of the BLAST program.

The hourly heating and cooling loads, zone air temperatures, and return air temperature heat gains computed by the building loads subprogram are used along with hourly weather data in the air handling system subprogram. The air handling system component characteristics and the control strategies are input by the user. Peak heating and cooling equipment capacities, required to meet zone loads, are calculated through preliminary simulations. Hourly energy consumption of the system components are calculated and monthly and annual values reported.

From the above description of the BLAST program, it is evident that the air handling system subprogram does not "feed back" to the loads portion of the program. In actual systems the feed back loop would tend to alter the zone loads and zone air temperatures as well as induce changes in the operation of the air handling system. The BLAST program is therefore in a sense a "quasi steady-state" program, incorporating what has commonly been presumed first order effects. Other research is currently underway to determine the effect on energy consumption of the dynamic interactions (minute-by-minute) of HVAC control systems.

\subsection{SMALL OFFICE BUILDING}

A schematic of the small office building used in this study is provided in figure 1. It is a three story lightweight structure measuring $30.48 \mathrm{~m}$ ( $100 \mathrm{ft}$ ) per side. The external wall consist of a metal curtain on the outside, an airspace, $5.1 \mathrm{~cm}$ (2 in) of insulation, and $1.3 \mathrm{~cm}(0.5 \mathrm{in})$ of gypsum board on the inside. Insulating glass is used, consisting of two $0.32 \mathrm{~cm}(1 / 8 \mathrm{in}$.) sheets separated by an airspace. The glass to wall area is 31 percent. Ten thermal zones are defined for the building and are shown in figure 1. 7one 1 consists of the interior of the first and second floors, and zones 2, 3, 4, 5 each comprise the first two floor's perimeter zones. The top floor's interior zone is labeled zone 6 and the top floor is perimeter zones are labeled 7 through 10. 
The hourly internal heat gain schedules due to occupants, lighting, and office electrical equipment are presented in figure 2. Thirty percent of the heat gain due to lighting is directed to the return air ducts. During normal working hours, the number of occupants, the extent of lighting and electrical usage are in the range commonly used for design purposes 2,3 . The nighttime and weekend schedules are adjusted for non-occupancy. No infiltration is considered during the occupied periods as it was assumed that the supply air fans pressurized the building. Likewise, infiltration is not considered during the unoccupied periods since the strategies investigated herein included intermittent or continuous operation of the supply air fans.

No alterations were made to the building envelope or occupancy schedules throughout the simulations. Changes made to the exterior envelope to conform to recommend standards ${ }^{4}$ for various climates were not considered because they would tend to mask differences in system performance with climate. Also, such changes were considered artificial since different building designs (not considered here) would result in at least as great a variance in building heating and cooling loads.

\subsection{WEATHER DATA}

The performance of HVAC systems is dependent on the weather either directly as in the performance of economizer cycles or indirectly as it effects zone heating and cooling loads. Typical Meteorological Year (TMY) and SOLMET ${ }^{5}$ hourly weather data were used in the simulations. The weather data were used for seven locations: Washington, DC; Nashville, TN; Madison, WI; Seattle, WA; Dodge City, KS; Lake Charles, LA; and Santa Maria, CA. The climates represented by these cities are wide ranging. Tables 1 lists the heating and cooling degree days which varied from 1498 to 7730 and from 84 to 2739 , respectively.

2 Energy Conservation with Comfort, the Honeywel1 Energy Conserver's Manual and Workbook, Honeywe11, 1979.

3 Reference Building Descriptions, DoC Ref.1.b.9, July 17, 1980, Draft Report.

4 ASHRAE Standard 90-75, "Energy Conservation in New Building Design," American Society of Heating, Refrigerating and Air-Conditioning Engineers, Inc., 1975.

5 Hourly Solar Radiation-Surface Meterological Observations, TD-9724, National nceanic and Atmospheric Administration, Environmental Data Service, August 1978. 


\section{SIMULATION OF HVAC SYSTEMS AND STRATEGIES}

Three systems commonly used in small office buildings were selected for investigation. The three systems are:

1. Constant volume terminal reheat system serving the entire building,

2. Two independently-operated constant volume terminal reheat systems serving separate zones of the building,

3. Variable-air volume terminal reheat system serving the entire building.

The first two systems have been popular in the past and are attractive on a first-cost bases. The more costly variable-air volume system has recently gain reacceptance due to improved control and sensor technology and because of its more efficient operation.

\subsection{SPACE CONDITIONING}

The air handling system capacities were sized such that during normal working hours, the zone dry-bulb temperatures did not exceed $25.6^{\circ} \mathrm{C}\left(78^{\circ} \mathrm{F}\right)$. Zone dewpoint temperatures were not allowed to exceed $18.3^{\circ} \mathrm{C}\left(65^{\circ} \mathrm{F}\right)$. The minimum zone air temperatures during occupied hours was $18.9^{\circ} \mathrm{C}\left(66^{\circ} \mathrm{F}\right)$. These comfort limits during occupied hours fall within the ranges established by the Federal Government's Fmergency Temperature Building Restrictions and the ASHRAE Standard 90-75; Energy Conservation in New Building Design.

In strategies employing temperatures setback during unoccupied hours, heating is applied at $13.9^{\circ} \mathrm{C}\left(57^{\circ} \mathrm{F}\right)$ and zone air temperatures were allowed to fall to $12.8^{\circ} \mathrm{C}\left(55^{\circ} \mathrm{F}\right)$. These setback temperatures are those which are commonly employed, and should not be considered as optimum values. Since it was felt that, for the systems investigated, the BLAST program could not realistically simulate temperature set-up for cooling, the zone air temperatures were allowed to float during unoccupied hours in order to prevent the air handling system from operating. Otherwise, the simulation program called for a simultaneous cooling and reheating of supply air to exactly meet the pre-determined zone cooling loads.

Minimum outdoor air quantities were specified as a percentage of the total system supply air. For the constant volume terminal reheat systems the minimum quantity used was approximately $.008 \mathrm{~m}^{3} / \mathrm{s}(17 \mathrm{cfm})$ per person. When supply air quantities were changed, the percent outdoor air was changed in order to maintain the same amount of minimum outdoor air. For the variable air volume system, the minimum outdoor air quantities were approximately the same as for the constant volume system when operating at peak block cooling loads. During peak block heating, the minimum outdoor air guantity for the variable volume system was reduced to approximately $\left(.0028 \mathrm{~m}^{3} / \mathrm{s}\right)(6 \mathrm{cfm})$ per person when no economy cycles were used. 


\subsection{CONSTANT VOL_UME TERMINAL REHEAT SYSTEM SERVING THE ENTIRE BUILDING}

The constant volume system consisted of a preheat co11, cooling coil and supply fan which distributed the conditioned alr to each zone. Heating and cooling capacity modulation was accomplished by hot water reheat colls in the supply air ducts leading to each zone.

This system is hereinafter referred to as the CV system. Thirty percent of the lighting heat gain in the model was directed to the return air ducts. Due to the small size of the building no return fan was considered. A portion of the combined return air from all the zones was exhausted and an equal amount of outside air introduced. All the strategies employed indicated that preheating to the extent needed to prevent the cooling coil from freezing was negligible, and therefore no preheat coil was considered.

The static pressure rise across the supply fan can have a large effect on fan energy consumption. The amount of rise is dependent on the size and design of the ductwork. A static pressure rise of $872 \mathrm{~Pa}$ (3.5 in. of water) was selected as a typical value for this type of system.

\subsubsection{System Strategies}

Case A-1 (Base Case)

The base case strategy was as follows:

1. The system operated during working hours from 7 a.m. to $7 \mathrm{p} . \mathrm{m}$., weekdays within the desired comfort range. This included one hour prior to occupancy to establish habitable conditions. Zone air temperatures were allowed to range from $18.9^{\circ} \mathrm{C}\left(66^{\circ} \mathrm{F}\right)$ to $25.6^{\circ} \mathrm{C}\left(78^{\circ} \mathrm{F}\right)$. Zone reheat coils were activated when the zone air temperatures fell below $21.7^{\circ} \mathrm{C}\left(71^{\circ} \mathrm{F}\right)$. Since zone 1 experienced a relatively constant cooling load, no reheat capahility was added to this zone.

2. During the remaining hours, $7 \mathrm{p} . \mathrm{m}$. to $7 \mathrm{a} \cdot \mathrm{m}$., and on weekends, the cooling coil was turned off and zone air temperatures allowed to float. Reheat coils were activated at zone air tempeatures of $13.9^{\circ} \mathrm{C}\left(57^{\circ} \mathrm{F}\right)$, reaching their maximum heating capacity at zone temperatures of $12.8^{\circ} \mathrm{C}\left(55^{\circ} \mathrm{F}\right)$.

3. The cold deck supply air temperature during working hours fixed at $16.7^{\circ} \mathrm{C}$ $\left(62^{\circ} \mathrm{F}\right)$. A $1.7^{\circ} \mathrm{C}\left(3^{\circ} \mathrm{F}\right)$ cold deck throttling range permitted the supply air temperatures to reach a minimum of $15^{\circ} \mathrm{C}\left(59^{\circ} \mathrm{F}\right)$ when the cooling coil experiences a small or near zero load. The cold deck temperature used was set at the maximum allowable temperature that would prevent the interior zone (which had the lowest sensible heat ratio) from exceeding a dew point temperature of $18.3^{\circ} \mathrm{C}\left(65^{\circ} \mathrm{F}\right)$.

4. During the working hours the minimum outdoor air fraction was fixed at .10 of the total supply air quality at all otheer times no outside air was introduced. 
Case A-2

This strategy was the same as case A-l with an enthalpy economy cycie added. In this cycle outdoor air quantity is proportioned with the return air such that the enthalpy of the mixture entering the cooling coil results in the smallest cooling coil load. The outdoor air quantity is, however, limited to the minimum required for ventilation as previously discussed.

Case $\mathrm{A}-3$

This strategy was the same as case A-l with a temperature economy cycle added. In this cycle outdoor air is introduced (above the minimum needed to satisfy ventilation requirements) only when the air temperature is equal to or below the supply air temperature.

Case $B-1$

The following modifications to the base case strategy A-1 were made.

1. The cold deck temperature was reset by the zone with the greatest sensible cooling demand. The cold deck temperature reset range was from $16.7^{\circ} \mathrm{C}\left(62^{\circ} \mathrm{F}\right)$ to $12.8^{\circ} \mathrm{C}\left(55^{\circ} \mathrm{F}\right)$.

2. The supply air quantities in all but the lower interior zone (zone 1 , refer to figure 1 ) were adjusted to satisfy the peak sensible cooling loads at a cold deck temperature of $12.8^{\circ} \mathrm{C}$ $\left(55^{\circ} \mathrm{F}\right)$. The lower interior zone supply air flowrate was sized to meet the cooling load at a cold deck temperature of $16.7^{\circ} \mathrm{C}$ $\left(62^{\circ} \mathrm{F}\right)$. Since the lower interior zone experienced a relatively constant cooling load, the effect of oversizing for this zone allowed the cold deck temperature to be controlled and reset by the remaining zones.

3. Reheat capability was added to zone 1. This was necessary since the lower cold deck temperatures expected during the summer months resulted in oversized cooling, capacity and overcooling of the space. Reheat coils in all zones were activated when zone air temperatures fell below $21.7^{\circ} \mathrm{C}\left(71^{\circ} \mathrm{F}\right)$.

4. A fixed outdoor air ratio of .15 was used during normal working hours. Due to the lower supply air quantities used in this strategy, the resulting outdoor air quantities introduced into the building were nearly the same as in the previously discusser strategies. During unoccupied hours, no outside air was introduced.

The intent of this strategy was to reduce the amount of reheat required to satisfy the space conditioning requirements of the exterior and upper interior zones. In addition, the supply fan energy consumption was reduced due to the lower average supply air flowrates. 
Case B-2

This strategy was the same as case $B-1$, but modified by the addition of an enthalpy economy cycle.

Case $\mathrm{C}-1$

This strategy was similar to case B-1 except that the cold deck temperature was reset by the outdoor temperature. Several simulations were required to establish a satisfactory reset schedule which would maintain space conditions within the comfort range during occupied hours. The reset control was $12.8^{\circ} \mathrm{C}\left(55^{\circ} \mathrm{F}\right)$ cold deck temperature at an outdoor temperature of $21.1^{\circ} \mathrm{C}\left(70^{\circ} \mathrm{F}\right)$, increasing proportionally with decreasing outdoor temperature of $16.7^{\circ} \mathrm{C}\left(62^{\circ} \mathrm{F}\right)$ at an outdoor temperature of $4.4^{\circ} \mathrm{C}$ $\left(40^{\circ} \mathrm{F}\right)$.

Case C-2

This strategy was the same as case C-l modified to include an enthalpy cycle.

Case $\mathrm{n}$

This strategy was the same as base case A-1 except that the system remained on continuously to maintain comfort. No outside air was introduced during the normally unoccupied hours.

\subsection{SYSTEM INCORPORATING TWO CONSTANT VOLUME TERMINAL REHEAT IINITS}

Many factors can influence the selection of zones in a building which should be controlled by one air handling system. One such consideration is the reduction in operating costs due to energy savings. The building envelope and the individual zone heating and cooling loads will vary from building to building so that zone optimization will also vary. Factors other than energy savings may decide which zones should be controlled by a system. This is especially true when selected zones are required to have continuous year round conditioning. Two separate systems such as the ones utilized in the simulation may be attractive to potential owners and operators in that it can offer improved flexibility, energy savings and possibly lower initial cost than more complex systems (such as VAV) serving the building.

The selection of zones to be controlled by one system was based on analysis of the zone cooling loads encounteered for Washington, DC climate. The lower interior (zone 1) and south-facing (zones 2, 7) zones were observed to have high year-round cooling loads and were controlled by one system. The remaining zones (zones $3,4,5,6,8,9,10$ ) were observed to have highly variable cooling and heating loads and were controlled by a second system. Thus, the second system provides the opportunity for a higher cold deck temperature. This in turn could result in reduced energy consumption due to less required reheat. 
A static pressure rise of $623 \mathrm{~Pa}$ (2.5 in. of water) was selected for eacn air handling system. Hereinafter, this system is referred to as a CV-CV System.

\subsubsection{CV-CV System Strategies}

In describing, the following strategies, the air handling system controlling zones 1,2 and 7 is 1 abeled $\mathrm{CV}-1$ and the system controlling the remaining zones of the building is labeled CV-2.

Case A-1 (Base Case)

1. Both $\mathrm{CV}-1$ and $\mathrm{CV}-2$ systems operated weekdays during working hours from $7 \mathrm{a} \cdot \mathrm{m}$. to $7 \mathrm{p} \cdot \mathrm{m}$. within the comfort range. This included one hour prior to occupancy to establish comfort conditions. Zone air temperatures were allowed to range from $18.9^{\circ} \mathrm{C}\left(66^{\circ} \mathrm{F}\right)$ to $25.6^{\circ} \mathrm{C}\left(78^{\circ} \mathrm{F}\right)$. Zone reheat coils were activated when zone air temperatures fell below $21.1^{\circ} \mathrm{C}\left(71^{\circ} \mathrm{F}\right)$.

As in the previous constant volume case, no reheat coils were applied to zone 1. For Santa Maria, reheat was also not required for zone 2.

2. During the remaining hours and on weekends, the cooling coil was turned off and zone air temperatures allowed to float. Reheat coils were activated, however, when zone air temperatures fell below $13.9{ }^{\circ} \mathrm{C}$ $\left(57^{\circ} \mathrm{F}\right)$.

3. The cold deck supply air temperature during working hours was fixed at $17.5^{\circ} \mathrm{C}\left(63.5^{\circ} \mathrm{F}\right)$ for $\mathrm{CV}-2$ and $16.7^{\circ} \mathrm{C}\left(62^{\circ} \mathrm{F}\right)$ for $\mathrm{CV}-1$. Both cold decks had throttling ranges of $1.7^{\circ} \mathrm{C}\left(3^{\circ} \mathrm{F}\right)$. These supply air temperatures were the maximum that could be achieved and still satisfy comfort space humidity conditions during the spring, summer, and fall months. Maximum supply air temperatures were selected as it was felt that most owners and operators would want to optimize chiller efficiency.

4. During working hours a fixed minimum outdoor air ratios of .10 for CV-1 and .09 for CV-2 is used. The resultant outdoor air quantities are the same as the previous system, corresponding to approximately $.008 \mathrm{~m}^{3} / \mathrm{s}$ (17 cfm) per person. Muring unoccupied hours, no outside air was introduced.

Case A-2

This strategy was the same as case A-1 with an enthalpy economy cycle added.

Case $\mathrm{A}-3$

This strategy was the same as case A-l with a temperature economy cycle added. 
Case B-1

During the winter months the cold deck temperature for $\mathrm{CV}-2$ was reset by the zone of greatest demand. The cold deck temperature was allowed to vary from a minimum of $17.5^{\circ} \mathrm{C}\left(63.5^{\circ} \mathrm{F}\right)$ to a maximum of $21.1^{\circ} \mathrm{C}\left(70^{\circ} \mathrm{F}\right)$. The winter months were defined as those months for which the outdoor temperature during the daylight hours 9 through 16 did not exceed $16.7^{\circ} \mathrm{C}\left(62^{\circ} \mathrm{F}\right)$ more than 10 percent of the time*.

Using the above definition for winter/summer conditions, it was not possible to implement strategies B-1, B-2, B-3, for Lake Charles and Santa Maria. Except for this modification, all other parameters remained the same as the base case.

Case B-2

Same strategy in case B-1, except with an enthalpy economy cycle added. The economy cycle here and in succeeding strategies were applied year round.

Case B-3

Same strategy as case B-1, except with a temperature economy cycle added. Case C-1

During winter months the cold deck temperature for $\mathrm{CV}-2$ was reset as a function of the outdoor temperature*. The cold deck temperature was reset as follows: $17.5^{\circ} \mathrm{C}\left(63.5^{\circ} \mathrm{F}\right)$ at an outdoor temperature of $12.8^{\circ} \mathrm{C}\left(55^{\circ} \mathrm{F}\right)$ increasing to a maximum value of $21.1^{\circ} \mathrm{C}\left(70^{\circ} \mathrm{F}\right)$ at an outdoor temperature of $10^{\circ} \mathrm{C}\left(50^{\circ} \mathrm{F}\right)^{* *}$. All other parameters remained the same as in the case B-1.

Case C-2

Same strategy as case C-1, except with an enthalpy economy cycle added ${ }^{* *}$. Case $\mathrm{C}-3$

Same strategy as case C-1, except with a temperature economy cycle added**.

* Derived from data supplied by Engineering Weather Data; Dept. of the Air Force, the Army, and the Navy, AFM 88-29, TM 50785, NAVFAC P-89, 1978 .

** As in strategies B-1, B-2 and B-3 the definition used for winter months did not permit implementation of strategies $\mathrm{C}-1, \mathrm{C}-2$ and $\mathrm{C}-3$ for Lake Charles and Santa Maria. 
Case D

Both air handling systems operated continuously to maintain com ort conditions. No outdoor air was introduced during the unoccupied perinds. All other conditions remained the same as the base case A-I.

\subsection{VARIABLE-AIR VOLUME TERMINAL REHEAT SYSTFM}

The variable-air volume system served all ten zones of the small office building. Zone supply air quantity was modulated in response to the zone heating or cooling requirements. Zone thermostats controlled supply air dampers from fully open at $25.6^{\circ} \mathrm{C}\left(78^{\circ} \mathrm{F}\right)$ to a selected minimum value at and below $24.4^{\circ} \mathrm{C}\left(76^{\circ} \mathrm{F}\right)$.

A supply fan with variable pitch inlet vanes was simulated with a fan efficiency of 65 percent in contrast to the 70 percent efficiencies used in the constant volume systems. Static pressure rise the fan at peak air flow conditions was indentical to the single constant volume system ( $872 \mathrm{~Pa}(3.5$ in. $\left.\mathrm{H}_{2} \mathrm{O}\right)$ ). A description of the various strategies simulated for the VAV system follows.

\subsubsection{VAV System Strategies}

Case A-1 (Base Case)

1. The system operated during working hours, $7 \mathrm{a} \cdot \mathrm{m}$. to $7 \cdot \mathrm{p} \cdot \mathrm{m}$. as the previous systems base case strategies already described. During these hours zone air temperatures ranged from $18.9^{\circ} \mathrm{C}\left(66^{\circ} \mathrm{F}\right)$ to $25.6{ }^{\circ} \mathrm{C}$ $\left(78^{\circ} \mathrm{F}\right)$. Zone reheat coils were turned on when zone air temperatures fell below $21.7^{\circ} \mathrm{C}\left(71^{\circ} \mathrm{F}\right)$. As in the other systems, zone 1 contained no reheat coils and in the case of Santa Maria, zone 2 reheat was turned off.

2. During the remaining hours and on weekends, the cooling coil was turned off and zone air temperatures allowed to float. Reheat coils were, however, activated when zone air temperatures fell below $13.9^{\circ} \mathrm{C}$ $\left(57^{\circ} \mathrm{F}\right)$.

3. The cold deck supply air temperature was fixed at $12.8^{\circ} \mathrm{C}\left(55^{\circ} \mathrm{F}\right)$ with a $1.7^{\circ} \mathrm{C}\left(3^{\circ} \mathrm{F}\right)$ throttling range. The cold deck was set at this value to insure adequate dehumidification during mild weather when zone supply air quantities may be reduced.

4. A minimum outdoor air fraction was fixed at .15 during working hours. The resultant outdoor air quantity was comparable to the two previous systems when the building experienced peak block cooling loads. During peak block heating and resultant air quantity was sufficient to meet a minimum recommended value of $.0028 \mathrm{~m}^{3} / \mathrm{s}(6 \mathrm{cfm})$ per person. During unoccupied hours no outside air was introduced. 
5. The variable air volume terminals had a minimum fraction of 0.2 . As previously stated, the maximum supply air was available at zone air temperatures of $25.6^{\circ} \mathrm{C}\left(78^{\circ} \mathrm{F}\right)$, falling to 20 percent of the maximum value at zone air temperatures of $24.4^{\circ} \mathrm{C}\left(76^{\circ} \mathrm{F}\right)$ and less.

Case A-2

This strategy was the same as the base case strategy, case A-1, modified by the addition of an enthalpy economy cycle.

Case A-3

This strategy was the same as base case A-1 modified by the addition of a temperature economy cycle.

Case B-1

The base case strategy, case $A-1$, was modified as follows:

1. The cold deck temperature was reset by the zone requiring the most cooling. The cold deck temperature reset limits were $12.8^{\circ} \mathrm{C}\left(55^{\circ} \mathrm{F}\right)$ to $16.7^{\circ} \mathrm{C}\left(62^{\circ} \mathrm{F}\right)$.

2. The supply air quality for the lower interior zone (zone 1) was readjusted to satisfy the cooling load at a cold deck temperature of $16.7^{\circ} \mathrm{C}\left(62^{\circ} \mathrm{F}\right)$ when the zone air damper was fully open. Due to the constant cooling load experienced by the lower interior zone, this adjustment was necessary in order to prevent the zone from controlling the cold deck temperature at the low value of $12.8^{\circ} \mathrm{C}\left(55^{\circ} \mathrm{F}\right)$. During the winter months when the cold deck temperature was expected to be in the neighborhood of $16.7^{\circ} \mathrm{C}\left(62^{\circ} \mathrm{F}\right)$, the interior zone supply damper would be fully open, whereas during the summer months the damper could modulate the supply air sufficiently to prevent overcooling. As a result, it was determined that the interior zone required no reheat.

Case B-2

This strategy was the same as case B-1, except with an enthalpy economy cycle added.

Case $B-3$

This strategy was the same as case $\mathrm{B}-1$, except with a temperature economy cycle added.

Case $\mathrm{C}-1$

This strategy was similar to case B-l strategy except that the cold deck temperature was reset by the outdoor temperature. The reset temperatures were as follows: $12.8^{\circ} \mathrm{C}\left(55^{\circ} \mathrm{F}\right)$ at an outdoor temperature of $21.1{ }^{\circ} \mathrm{C}\left(70^{\circ} \mathrm{F}\right)$ increasing proportionally with decreasing outdoor temperature to $16.7^{\circ} \mathrm{C}$, $\left(62^{\circ} \mathrm{F}\right)$ at an outdoor temperature of $4.4^{\circ} \mathrm{C}\left(40^{\circ} \mathrm{F}\right)$. 
Case $\mathrm{C}-2$

This strategy was the same as case C-1 strategy with an enthalpy economy cycle added.

Case $\mathrm{C}-3$

This strategy was the same as case C-1 strategy with a temperature economy cycle added.

Case D

Comfort conditions were maintained continuously throughout the day and night all other conditions remain the same as the base case (A-1) strategy and no outside air was introduced into the space during the unoccupied hours. 


\section{RESULTS AND DTSCUSSION}

Annual energy consumption results are presented in tables 2 through 8 for the three HVAC systems and the seven cities discussed previously. Each table lists hot water, chilled water and fan annual energy consumption in the upper portion of each block for each of the three HVAC systems. The first column in each table briefly describes the strategy employed for the systems. For a selected strategy, comparisons between HVAC systems can be made for the annual energy consumption for chilled water, hot water and fan energy consumption. The numbers appearing in the lower portion of each block represent the ratios of energy consumption relative to the base case strategy (case A-1) for that particular system. In the ensuing discussions, that following abbreviations $\overline{\text { are }}$ used to describe each HVAC system:

CV system: constant volume terminal reheat system serving the entire building,

CV-CV system: two independently operated CV systems; one serving zones 1, 2, and 7 and the other serving the remaining zones.

VAV system: variable air volume terminal reheat system serving the entire building.

Fach strategy presented in tables 2 through 8 differ in some respects for each of the three systems due to constraints imposes by the system. For example, in the base case strategy (case $\mathrm{A}-1$ ) the cold deck supply air temperatures for the $\mathrm{CV}$ system was $16.7^{\circ} \mathrm{C}\left(62^{\circ} \mathrm{F}\right)$; for the $\mathrm{CV}-\mathrm{CV}$ system they were $16.7^{\circ} \mathrm{C}\left(62^{\circ} \mathrm{F}\right)$ for the first air handling unit and $17.5^{\circ} \mathrm{C},\left(63.5^{\circ} \mathrm{F}\right)$ for the second; for the $\mathrm{VAV}$ system the cold-deck temperature was $12.8^{\circ} \mathrm{C}\left(55^{\circ} \mathrm{F}\right)$. The differences in some parameters for the same basic strategy in each of the three systems and the reasons for selection were discussed in the previous section.

\section{I COMPARISON OF SYSTEMS - (tables 2 through 8)}

The results of tables 2 through 8 indicate that for each of the different strategies the VAV system is the most efficient system (least fan, chilled water and hot water annual energy consumption) for all seven cities.

In comparing the base case strategy ( $A-1$ ) for the VAV system with strategy B-2 (zone controlled cold deck with enthalpy economy cycle) for the CV-CV system, it is found that the former system uses less hot water and fan energy in all seven cities. It also uses less chilled water in all cities, except Madison and Seattle. Since for each strategy the VAV system generally outperforms the other two systems, the ensuing discussion centers on comparison of the CV-CV and $\mathrm{CV}$ systems.

In comparing the $\mathrm{CV}$ and $\mathrm{CV}-\mathrm{CV}$ system for the cases $\mathrm{A}-1$ through $\mathrm{A}-3$, the hot water and chilled water energy consumption are approximately the same. This is expected since in these cases the $\mathrm{CV}-\mathrm{CV}$ is operating as if it were a single system ( $C V$ system). Comparisons in fan energy consumption for these two systems should not be made, since in each system differences in duct design and 
installation could alter the relative values. (In the present study, a static pressure rise of $623 \mathrm{~Pa}\left(2.5\right.$ in $\left.\mathrm{H}_{2} \mathrm{O}\right)$ was used for each of the supply fans in the $\mathrm{CV}-\mathrm{CV}$ system whereas a value of $872 \mathrm{~Pa}\left(3.5\right.$ in $\mathrm{H}_{2} \mathrm{O}$ ) was used for the $\mathrm{CV}$ system.)

In comparing zone-controlled cold deck strategy (case B-1) for the CV and $\mathrm{CV}-\mathrm{CV}$ system, both systems use approximately the same energy for chilled water. However, the percent savings in hot water energy consumption (reheat energy) for the $\mathrm{CV}-\mathrm{CV}$ system over the $\mathrm{CV}$ system range from 21 percent to 35 percent, increasing with decreasing number of cooling degree days in each city. The large consumption in hot water for the zone-control CV system is due to the fact that the interior zone requires reheating to prevent overcooling of the space when the cold deck supply air temperature is low. For strategy B-2, the percent savings in hot water of the CV-CV system over the CV system is approximately the same as case B-1 when an enthalpy economy cycle is added.

In the zone-controlled and outdoor air-controlled cold deck strategies (case $B$ and C), Lake Charles and Santa Maria are not included, since cold deck reset was applied only during the winter months and thus did not apply for these cities. As discussed in section 4.3.1, the winter months were defined as those months for which the outdoor temperature during the daylight hours 9 through 16 did not exceed $16.7^{\circ} \mathrm{C}\left(62^{\circ} \mathrm{F}\right)$ more than 10 percent of the time.

As mentioned previously, it might be possible to further improve the performance of the CV-CV system by optimizing the zoning of each system according to the climate. In addition, variations in performance will result if the zonecontrolled strategy (case B) is applied year round. In such a case deck supply air temperature would have to be in a lower range, (for example, $12.8^{\circ} \mathrm{C}\left(55^{\circ} \mathrm{F}\right.$ ) to $17.5^{\circ} \mathrm{C}\left(63.5^{\circ} \mathrm{F}\right)$ instead of $17.5^{\circ} \mathrm{C}\left(63.5^{\circ} \mathrm{F}\right)$ to $\left.21.1^{\circ} \mathrm{C}\left(70^{\circ} \mathrm{F}\right)\right)$. These possibilities were, however, not investigated.

Increased savings in chilled water consumption is achieved by the CV-CV system over the CV system for case B-2. This is accomplished by allowing the economy cycle to offset cooling coil energy consumption at higher outdoor temperatures. This was possible since the cold deck temperature for one air handling unit in the $\mathrm{CV}-\mathrm{CV}$ system was reset to $21.1^{\circ} \mathrm{C}\left(70^{\circ} \mathrm{F}\right)$, whereas for the $\mathrm{CV}$ system (as we 11 as the second air handling unit on the $\mathrm{CV}-\mathrm{CV}$ system), the allowable maximum cold deck temperature was $16.7^{\circ} \mathrm{C}\left(62^{\circ} \mathrm{F}\right)$.

Hot water consumption is also less for the CV-CV system as compared to the CV system for strategy C-1 (cold deck temperature reset by outdoor air temperature). The percent savings in hot water generally follow the same trend as in the zonecontrolled strategies (cases B-1, B-2, B-3), however, they average approximately 10 percent more in energy savings. Savings in chilled water energy consumption are also realized and range from 5 percent to 13 percent. The results for cases $\mathrm{C}-1$ and $\mathrm{C}-2$ should be regarded as approximate since in some cities the simulations indicated variations in the number of hours for which there were unmet cooling loads. An unmet cooling load is defined as the additional cooling required by a zone which cannot be met by the zone air handling system. In the worst case, the maximum percentage of unmet cooling loads in any zone did not exceed 6 percent, with the remaining zones having a much lower percentage. 


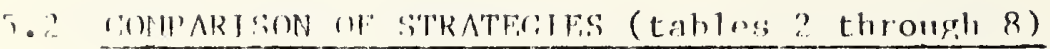

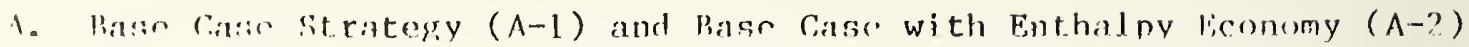

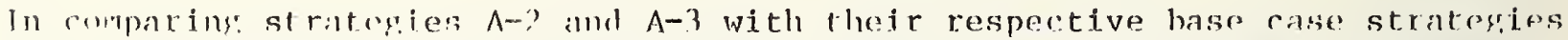

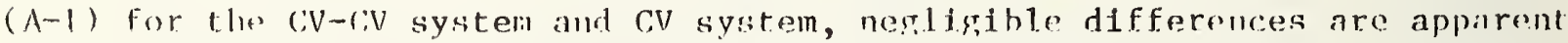
in the hot and chilled water and fan chersiv consumption. Therefore, in the onsuins discussion of strategies $A-2$ and $A-3$, comparisons are made between the CV aml VAV system with the results for the CV system also applyingr to the C,V-C,V

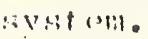

lian linersy consumption: There are negligible differences in fan energy consumption for strateyy A-2 compared to strategy $\wedge-1$ for all systems and for : 11 : sovoll ritios.

Iof Water Fucryy Consumption: There is all increase in hot water energy collinmetion for the C.V system over the base case ranging from 3 percent to 7 priont for the five cities. Seattle and Santa Maria indicated a higher luerontase increase of approxinately 12 percent. The VAV systen indicates a much sillaler incrase in hot water energy consumption, ranging from 1 percent (1) ? proent for all seven cities.

The incroass is due primarily to the throttling of the cooling coll to slisht ly lower cold deck tomperatures (the maximum throttling was $1.8^{\circ} \mathrm{C},\left(3^{\circ} \mathrm{F}\right)$ ), which, if III) modulated by roheat would cause overcooling of zones. This is especially tru iu mill clinates such as Seattle and Santa Maria where more hours are avilialle for operation with an economy cycle.

'Th VAV System "xhibits a smaller increase in the amount of reheat energy corlsumption than the C.V system when hoth systems include enthalpy economy cycles. Botli systems have approximately the same size coolinf, coil since at dosign conditions they both nust neet similar block (total) conling loads. As thu resultis inlicate, much less chilled water is used by the VAV system, implying thil llu coolinis coil for this system is operating most of the time at part load conditions. Since the conlins, coil for the VAV system is throteled hack most of the timo, any decrease in the cooling coll load (by the addition of an (erommizer) will not substantially increase the throttling.

Chillod Wator Finorsy Consumption: There is a wirle variation in savings in chillel water curessy consumption by employing an enthalpy economy cycle, as shown in thro following table:

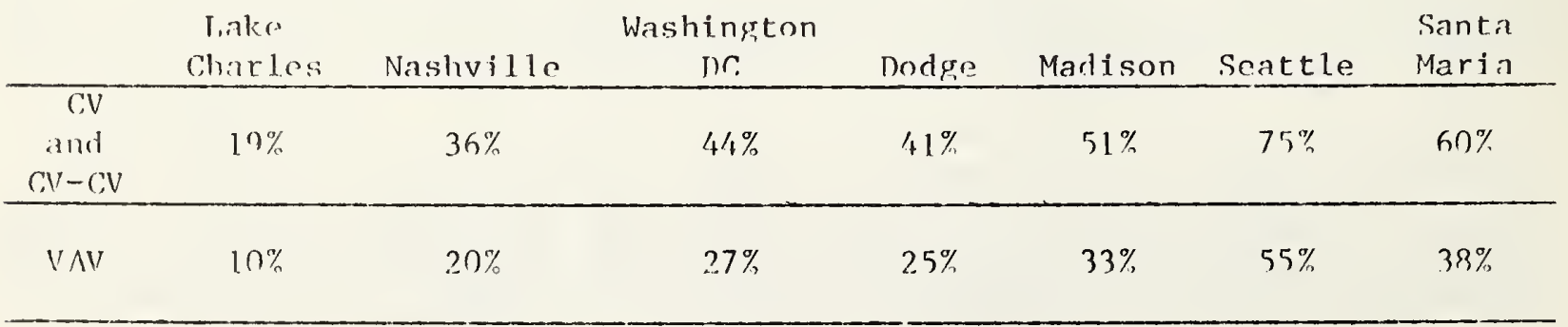


where the percent savings are with respect to the base case strategy A-1. The savings, as expected, generally increase with decreases in the number of cooling, degree days (see Table 1). The VAV system shows less savings with respect to its base case strategy, since with less the supply and return air flow rates are reduced in mild and cold weather, with less reheating being applied than the CV system, and the cooling coil load is small. The CV system, for the same outdoor conditions, will have a larger cooling coil load and introducing outside air to reduce the cooling coil load will therefore have a much greater effect on the $\mathrm{CV}$ system than the VAV system.

B. Temperature (case A-3) and Enthalpy (case A-2) Economy Cycles Added to the Base Case Strategy

Fan Energy: As in the previous case there are negligible differences in fan energy consumption for case A-3 (temperature economy cycle) as compared to case A-2 (enthalpy economy cycle) for all systems in the seven cities.

Hot Water Energy Consumption: For the CV system there is a one to two percent savings in hot water energy consumption for case A-3 as compared to case A-2 in the five cities, although there is still an increase in hot water energy consumption with respect to the base case, A-1. Savings for Seattle and Santa Maria range slightly higher, from two to five percent, relative to case $\mathrm{A}-2$. The VAV system, in general, indicates negligible differences between strategies $\mathrm{A}-2$ and $\mathrm{A}-3$.

Chilled Water Energy: The following table lists the percentage savings in chilled water energy consumption by using an enthalpy economy cycle (case A-2) as compared to a temperature economy cycle (case A-3), for the $\mathrm{CV}$ and VAV systems.

\begin{tabular}{lccccccc} 
& $\begin{array}{c}\text { Lake } \\
\text { Charles }\end{array}$ & Nashville & $\begin{array}{c}\text { Washington } \\
\text { DC }\end{array}$ & Dodge & Madison & Seattle & $\begin{array}{c}\text { Santa } \\
\text { Maria }\end{array}$ \\
\hline CV & $7 \%$ & $11 \%$ & $11 \%$ & $11 \%$ & $16 \%$ & $39 \%$ & $40 \%$ \\
\hline VAV & $8 \%$ & $10 \%$ & $13 \%$ & $11 \%$ & $13 \%$ & $36 \%$ & $29 \%$ \\
\hline
\end{tabular}

As the above table indicates, the percentage savings chilled water energy consumption for case A-2 as compared to case A-3 generally increases with a decrease in the number of cooling degree days. The increases are primarily due to two effects. One effect in using a temperature economy cycle is that outside air is only introduced when the outside air temperature is less than or equal to the cold deck temperature. For an enthalpy economy cycle (as well as return air economy cycle), outside air is introduced when its enthalpy is less than or equal to the return air enthalpy. Thus, outside air in the enthalpy economy cycle reduces the cooling coil load at higher outdoor temperatures (above the cold deck temperature) than the temperature economy cycle. The dramatic savings in chilled water consumption for Seattle and Santa Maria as compared to the other five cities listed in the table can be understood with 
the aid of the third column in table 1. These numbers represent the percentage of temperature bin hours encountered between outdoor temperatures ranging from $13.9^{\circ} \mathrm{C}\left(57^{\circ} \mathrm{F}\right)$ to $22.2^{\circ} \mathrm{C}\left(72^{\circ} \mathrm{F}\right)$ for the daylight hours from 9 a.m. to $4 \mathrm{p} . \mathrm{m}$. The outdoor temperature of $13.9^{\circ} \mathrm{C}\left(57^{\circ} \mathrm{F}\right)$ represents an approximate value above which a temperature economy cycle (for cold deck temperatures set at $13.9^{\circ} \mathrm{C}$ $\left.\left(57^{\circ} \mathrm{F}\right)\right)$ is inoperable. The representative outdoor temperature of $22.2^{\circ} \mathrm{C}\left(72^{\circ} \mathrm{F}\right)$ is used as a typical return air temperature for which an enthalpy economy cycle operating at or below this outdoor temperature can partly offset the cooling coil load. It is evident from table 1 that an enthalpy economy cycle is very effective for Seattle and Santa Maria since a significant portion of the operating hours are spent within this temperature range.

\section{Base Case Strategy (A-1) and Zone-Controlled Cold Deck Strategy (B-1)}

Fan Energy Consumption: For the CV system, fan energy consumption is lower for the zone-controlled cold deck stratety (case B-1) as compared to the fixed cold deck strategy (case $A-1$ ). The decreases in fan energy consumption range from 25 to 28 percent for the seven cities. The savings are realized since all but the interior zone air flow rates are reduced for case B-1 to meet peak cooling demands at a $12.8^{\circ} \mathrm{C}\left(55^{\circ} \mathrm{F}\right)$ cold deck temperature. In the simulations, the interior zone air flow rate remained the same as the base case (sized to meet peak cooling loads at a $16.7^{\circ} \mathrm{C}\left(62^{\circ} \mathrm{F}\right)$ ) in order to allow the reamining zones to control the cold deck temperature.

No changes in fan energy consumption are encountered with the CV-CV system since zone air flow rates remain the same as in the base case, $\mathrm{A}-1$.

The VAV system shows a general increase in fan energy for zone-controlled cold deck. For Nashville, Washington, DC, and Madison the percentage increase ranges from 11 to 14 percent. The remaining cities show smaller increases, averaging approximately 2 percent. The increase in fan energy consumption is due primarily to the variable the air volume dampers opening to a larger extent than for the base case. With a zone-controlled cold deck strategy, cooling capacity is reduced sequentially by first increasing the cold deck temperature. Since zone cooling capacity is reduced by this method, a reduction in zone supply air quantities is not needed. In fact, zone air quantities generally increase with increasing cold deck temperature (for a given zone cooling load) until at least one of the 10 zones with the greatest cooling demand has a maximum zone air damper opening. Thereafter, further reductions in zone cooling capacities is accomplished by gradually closing the dampers.

Hot Water Energy Consumption. The following table is a summary of the percent decrease in hot water energy consumption for zone-controlled cold deck (case $\mathrm{B}-1$ ) as compared to the fixed cold deck (case A-1). 
linke

Washing,ton

Sant:a

(itorles

Nashiville

inc.

Dodge

Madtson

Seatte

Marfa

(:V

$10 \%$

$-14 \%$

$-26 \%$

$-2 \% \%$

$-32 \%-2.7 \%$

$-6 \%$

$(: V-C) \quad N / A$

$12 \%$

$16 \%$

$14 \%$

$16 \%$

$2.1 \%$

$N / \Lambda$

VAV

$21 \%$

$31 \%$

$27 \%$

$9 \%$

$19 \%$

$13 \%$

$26 \%$

For the CV system hot water encryy collsumption increases when employing a zone controlled cold deck. The reason for the increase is due to the fact that the interior zone requires the addlion of a reheat coll in order to prevent overcooling of the space when the cold deck tomperature is low. By oversizfng. the coolings capactly in the luterfor zone, the remaining zones can thereby control the cold deck tomperature. The rosults vary widely from city to city since the increases in relieat concryy neoded to satisfy interior zone cooling are offset by decreases in the requfred reheat energy in the rematning, zones (when the cold deck tomperature is hifrh).

IIsing a zono controlled cold deck stratesy in the CV-CV and VAV systems results iı a higher porcontage savings over the hase case, $\Lambda^{-1}$. For the CV-CV system the savingss rangre from 12 to 21 percent, generally increasing with a decrease in the number of cooling degree days. The VAV system employing zone controlled coldl deck sliows savings over the hase case ranging from 9 to 31 percent.

The grencrally higher savings in hot water energy consumption for the VAV system as compared to the CV-CV system is in part attributable to those periods when mild weather conditions prevail. Duringr these times a maximum supply air temperature is sufficient to meet the peak zone cooling loads and simultaneously provide a minimum of reheat to those zones which require heating. The savings do not appear to follow any correlation with degree days, as indicated in the above table.

Chilled Water Energy Consumption. Fmploying zone controlled cold deck for the CV system results in savings over the base case ranging from 7 percent for take Charles to 19 percent for Seattle. The savings generally increase with a decrease in cooling degree days except for Santa Maria where the savings are approximately 11 percent.

Savings for the CV-CV system follow the same trend as the CV system, however, the magnitudes are less; ranging from 6 percent for Nashville to 15 percent for Seattle.

The percent savings over the base case for the VAV system are generally smaller than those for the $\mathrm{CV}-\mathrm{CV}$ and $\mathrm{CV}$ system. The savings range from 1 to 8 percent for 6 cities and is approximately 11 percent for Madison. 
The lower percent savings for the VAV system as compared to the $\mathrm{CV}$ and $\mathrm{CV}-\mathrm{CV}$ systems may be understood in part by examining the cold deck reset control for this system during different seasons for the year. During the summer as well as mild weather periods the VAV system modulates zone cooling capacities by determining the maximum permissable cold deck temperature which will cause the zone of greatest cooling demand to operate with the dampers fully open. During these occasions the dampers in the remaining zones will be partially closed in order to reduce cooling capacities to match zone cooling loads. Since the zone supply air dampers have zone operating range (capable of modulating zone supply air flowrates by 80 perecnt) the zone cooling loads can also be met by maintaining a fixed cold deck temperature and modulating the dampers alone. In the latter case the zone air dampers would open and close to a greater extent than the former case to meet the same zone cooling loads. Thus with or without zone controlled cold deck during mild or summer weather, the cooling coil load will be nearly the same, approximately the sum of the zone cooling loads and return air heat gains. During the winter months, however, when most of the zones are heating and the remaining zones operating at less than maximum air flow rates, savings are realized since the cold deck temperature is reset upwards and supply air flow rates are lower.

The additional complexity of the zone controlled deck for the VAV system in contrast to the $\mathrm{CV}$ and $\mathrm{CV}-\mathrm{CV}$ zone controlled system is reflected in the lack of a consistent trend in hot water and chilled water savings with cooling and heating degree days. The amount of savings using zone controlled cold deck on VAV systerns may be dependent on other meteorological factors such as solar radiation, cloud cover, and dafly means and extreme temperatures during the surnmer, winter, and intermediate months. Other factors which will determine savings are the minimum air flow ratio of the VAV system as well as the thermal responsiveness of the various zones within the building. The latter factor is of course applicable to the $\mathrm{CV}$ and $\mathrm{CV}-\mathrm{CV}$ systems.

D. Temperature Economy Cycle (case B-3) and Enthalpy Economy Cycle (case B-2) for Zone-Controlled Cold Deck Systems

Fan Energy Consumption: Tables 2 through 8 indicate negligible differences in fan energy consumption between cases $\mathrm{B}-2$ and $\mathrm{B}-3$ for all systems in the seven cities.

Hot Water Energy Consumption: For the $\mathrm{CV}$ system there is a one to two percent savings in hot water energy consumption for strategy $B-3$ as compared to strategy B-2 in the five cities. Savings relative to strategy B-2 for Seattle and Santa Maria range slightly higher, from 2 to 5 percent. Savings for the CV-CV system are nearly identical to the CV system results. The VAV system in general indicates negligible differences between strategies $\mathrm{B}-2$ and $\mathrm{B}-3$.

Chilled Water Energy Consumption: For the CV system the percentage decrease in chilled water consumption for zone-controlled cold deck systems with enthalpy economy cycle (case B-2) as compared to zone-controlled cold deck with temperature economy cycle (case $\mathrm{B}-3$ ) is the same (within 3 percent) for five cities as in the results stated for cases $\mathrm{A}-2$ and $\mathrm{A}-3$ (fixed cold deck temperatures). 
The $\mathrm{CV}-\mathrm{CV}$ system indicates nearly identical results as the CV system for five cities. The results, however, are not reported for Lake Charles and Santa Maria since in these cities it was not possible to use a zone controlled cold deck temperature strategy.

Likewise, the VAV system shows similar percent decreases in chilled water consumption as found in the comparison of cases $\mathrm{A}-2$ and $\mathrm{A}-3$.

\section{E. Zone-Controlled (case B-1) and Outdoor Air-Controlled (case C-1) Cold Deck Strategies}

Fan Energy Consumption: For the $\mathrm{CV}-\mathrm{CV}$ and $\mathrm{CV}$ system there are negligible differences in fan energy consumption for the outdoor-air controlled cold deck (case $\mathrm{C}-1$ ) and the zone-controlled cold deck (case B-1) strategies. For the VAV system savings in fan energy using outdoor-air controlled cold deck strategy as compared to the zone-controlled cold deck strategy range from 4 to 7 percent for Nashville, Washington, DC, Dodge, and Madison; the remaining cities show negligible differences.

Hot Water Energy Consumption: The following table lists the approximate decrease in hot water consumption by using zone-controlled cold deck temperature (case B-1) as compared to the outdoor air-controlled cold deck temperature (case $\mathrm{C}-1$ ).

\begin{tabular}{lccccccc} 
& $\begin{array}{c}\text { Lake } \\
\text { Charles }\end{array}$ & Nashville & $\begin{array}{c}\text { Washington } \\
\text { DC }\end{array}$ & Dodge & Madison & Seattle & $\begin{array}{c}\text { Santa } \\
\text { Maria }\end{array}$ \\
\hline $\mathrm{CV}$ & $23 \%$ & $22 \%$ & $3 \%$ & $14 \%$ & $9 \%$ & $13 \%$ & $13 \%$ \\
\hline $\mathrm{CV}-\mathrm{CV}$ & $\mathrm{N} / \mathrm{A}$ & $3 \%$ & $1 \%$ & $0 \%$ & $-2 \%$ & $-1 \%$ & N/A \\
\hline $\mathrm{VAV}$ & $5 \%$ & $7 \%$ & $4 \%$ & $4 \%$ & $1 \%$ & $-14 \%$ & $5 \%$ \\
\hline
\end{tabular}

As the above table indicates, all systems generally show a decrease in hot water consumption. For the $\mathrm{CV}$ system, the savings range from 3 percent to 23 percent. The $\mathrm{CV}-\mathrm{CV}$ system indicates negligible differences in hot water consumption for all cities. Percent savings in hot water consumption for the VAV system ranges from 1 percent to 7 percent for 6 cities. Seattle, however, indicates an increase of 14 percent.

Chilled Water Energy Consumption: The following table lists the percent savings in chilled water consumption using zone-controlled cold deck (case B-1) compared to an outdoor air-controlled cold deck (case $\mathrm{C}-1$ ). 
Lake

Washington

Santa

Charles

Nashville DC

Dodge

Madison Seattle

Maria

\begin{tabular}{lccccccc}
\hline CV & $14 \%$ & $14 \%$ & $3 \%$ & $11 \%$ & $10 \%$ & $11 \%$ & $12 \%$ \\
\hline CV-CV & N/A & $1 \%$ & $0 \%$ & $0 \%$ & $0 \%$ & $-1 \%$ & N/A \\
\hline VAV & $4 \%$ & $1 \%$ & $1 \%$ & $1 \%$ & $1 \%$ & $-7 \%$ & $1 \%$ \\
\hline
\end{tabular}

For the CV system savings in chilled water consumption range from 10 percent to 14 percent for 6 cities; Washington indicates a much lower savings of 3 percent.

Negligible changes in chilled water savings is apparent for the CV-CV system, as well as for the VAV system. Seattle, however, exhibits a similar anamolous result in chilled water consumption as it does for hot water consumption. An increase of 7 percent in chilled water energy consumption results when a zone controlled strategy is employed rather than an outdoor air-controlled strategy.

It is apparent that the comparative results in hot water and chilled water energy consumption for the outdoor-air controlled strategies (case C-l) with the zone-controlled cold deck strategies (case B-1) can vary from city to city. A number of effects can be identified which can cause these variations.

The percent changes in hot water and chilled water energy consumption using an outdoor temperature controlled cold deck over a zone controlled strategy can vary because the former strategy does not optimize according to zone and building heating and cooling loads. In some instances the outdoor temperature may dictate a cold deck temperature which is lower than that which would have occurred if the system were zone controlled. In this instance, chilled water consumption and hot water consumption (for zones which require heating) would be higher than the zone-controlled cold deck strategy.

Zone cooling and heating requirements will depend not only on outside air temperature but also on changing internal heat gains, solar heat gains, and how responsive each zone is in translating these gains into zone loads. These factors will also vary for different building designs, orientation, and occupancy (usage) schedules so that optimum outdoor air controlling cold deck strategies require careful attention for each building and climate. These temperatures must be selected to insure few hours for which there is undercooling yet high enough cold deck temperature and outdoor temperature as to be effective.

Finally, for buildings which are highly responsive to solar and internal loads, outdoor cold deck temperature reset will not be as effective as applying the same strategy to a building which is more responsive to changes in the outdoor temperature. Obviously, in the former building a low enough outdoor temperature must be selected to reset the cold deck temperature in order to meet the 
large temperature-independent heat gains. In these cases zone controlling would be expected to generate even higher energy savings.

Base Case Strategy (cases A-1) with Continuous Conditioning Strategy (case D)

From tables 2 through 8 it is apparent that the continuous conditioning strategy (case D) compared to the base case strategy uses much more fan, hot water, and chilled water energy. In case D strategy, the CV-CV system is operating as if it were a single system so that the following discussion for the $\mathrm{CV}$ system applies to the $\mathrm{CV}-\mathrm{CV}$ system as well.

Fan Energy Consumption: The ratio of fan energy consumption for case D strategy compared to the base case A-1 ranges from 1.5 to 2.5 for the seven cities. The VAV system and the $\mathrm{CV}$ system have approximately the same ratio for each city. The energy consumption for case $D$ is less than the ratio of total annual hours to occupied hours (approximately 2.8 ). This is due to the fact that the fans operated intermittantly during unoccupied hours to satisfy zone heating or cooling loads.

Hot Water Energy Consumption: The ratio of hot water energy consumption for case D strategy compared to the base case for the CV system ranges from 3.5 to 4.0 for the seven cities. For the VAV system this ratio ranges from 2.8 to 4.2 for five cities; Lake Charles and Santa Maria having ratios of 5.9 to 8.3, respectively.

The extreme high increases in reheat energy (above the ratio of annual hours to occupied hours) is due primarily to reheating that is needed during the normally off hours during the summer, as was observed in the monthly energy usage summaries obtained in the simulations. During these periods the internal heat gains are low so that only a small amount of zone cooling is required. In order to achieve the low cooling capacities for the VAV and CV systems, the zone supply air temperature must be increased by reheating. Another contributing factor is the raised zone air temperatures during unoccupied periods for winter heating.

Chilled Water Energy Consumption. Chilled water energy consumption ratios for the CV system range from 2.2 to 2.7 for the seven cities. For the VAV system the ratios are lower, ranging from 1.4 to 1.9 . The lower ratios exhibited for chilled water energy consumption as compared to hot water consumption is primarily due to the small amount of cooling required during the unoccupied hours. The VAV system exhibits a lower ratio than the CV system since zone cooling capacities can be lowered by reducing the zone supply air flow rates. 
Using the BLAST computer program, a typical small office building was modeled along with commonly employed systems and strategies. Annual energy consumption results (at the systems level) are presented for hot water, chilled water and circulating fans for seven geographical locations. The systems modeled were a variable air volume, (VAV) reheat system, a constant volume terminal reheat (CV) system, and two independently operating constant volume terminal reheat $(\mathrm{CV}-\mathrm{CV})$ systems.

For comparable control strategies, the variable air volume (VAV) system (with a 0.2 minimum air volume ratio) exhibited the least energy consumption for chilled water, hot water and circulating fan. The system incorporating two independently operating constant volume terminal reheat units ( $\mathrm{CV}-\mathrm{CV}$ ) ranked second in energy consumption while the single constant volume terminal reheat (CV) system ranked last. The results are summarized in the bar chart of Figure 3 for the base case strategy, (case A-1). Moreover, the VAV system with the least efficient strategy (excluding continuous operation) (case A-1) generally used less chilled water and reheat hot water than the CV system with a fixed cold deck and enthalpy economy cycle (case $\mathrm{A}-2$ ) and the $\mathrm{CV}-\mathrm{CV}$ system with a zone-controlled cold deck and enthalpy economy cycle (case B-2). The strategies for the latter two systems were judged the best of the ones investigated in this report and are presented in figure 4.

One of the more effective strategies investigated for reducing chilled water energy consumption incorporated the use of economy cycles, particularly enthalpy economy cycles. Figure 5 summarizes the relative effectiveness of employing enthalpy economy cycles for the three systems in seven cities. For each HVAC system, the percent savings in chilled water energy consumption for a fixed cold deck strategy with an enthalpy economizer (case A-2) relative to a fixed cold deck temperature alone (case A-1) was found to be approximately equal to the percent savings in chilled water energy consumption for a zonecontrolled cold deck strategy with enthalpy economizer (case B-2) relative to a zone controlled cold deck temperature alone (case $\mathrm{B}-1$ ).

The results described above were found to apply for the resulting increases in hot water energy consumption when economy cycles are employed. Therefore, the results presented in figure 5 represent the energy effectiveness of enthalpy economy cycles when added to either a fixed cold deck strategy (case A-2 versus case $\mathrm{A}-1$ ) or a zone-controlled cold deck strategy (case B-2 versus $\mathrm{B}-1$ ).

As indicated in figure 5, the percent savings in chilled water energy consumption resulting from the addition of enthalpy economy cycles follow the same trends for all three HVAC systems in the seven cities. A discussion of these trends with locality was made in Section 5.

Referring to figure 5, the VAV system indicates the smallest chilled water savings when enthalpy economy cycles are added, ranging from 3 percent to 55 percent depending on locality. The chilled water savings for the CV and CV-CV systems are approximately the same in magnitudes and trends. The smallest savings (approximately 18 percent) are for Lake Charles and the largest are for Seattle and Santa Maria (55 percent to 76 percent). 
Figure 5 also indicates that for all three systems, the percent increases in hot water energy consumption are small when enthalpy economy cycles are employed. The VAV system indicates a maximum increase of approximately 3 percent whereas for the $\mathrm{CV}$ and $\mathrm{CV}-\mathrm{CV}$ systems the increases are slightly higher; ranging from 2 percent to 12 percent. As discussed in Section 5 these increases are primarily due to the automatic throttling back (by as much as $1.7^{\circ} \mathrm{C}\left(3^{\circ} \mathrm{F}\right)$ ) of the cold deck supply air temperature when outside air is used to offset the cooling coil load.

Figure 6 show results for percent changes in hot and chilled water energy consumption when a temperature economizer is added to a zone-controlled cold deck (case $\mathrm{B}-3$ relative to case $\mathrm{B}-1$ ) or added to a fixed cold deck (case $\mathrm{A}-3$ relative to case $A-1$ ). In figure 6 , the trends in chilled water savings with locality using temperature economy cycles are very similar to those found in using enthalpy economy cycles (figure 5) however; the magnitudes of the savings are reduced by approximately 10 percent to 30 percent, with the largest reductions occurring for Seattle and Santa Maria. As discussed in Section 5, the larger difference in chilled water savings for these two cities are attributable to the greater number of hours for which the outdoor temperature ranges between the cold deck temperature and return air temperature. For this outdoor temperature range, a temperature economy cycle is relatively ineffective as compared to enthalpy or return air economy cycles.

Figure 6 indicates a small increase in hot water energy consumption when temperature economy cycles are added. The VAV system indicates the smallest increase (approximately 1 to 3 percent) of the three systems. The remaining two systems show increases ranging from approximately 3 percent to 7 percent.

For the small office building model, adding a zone-controlled cold deck strategy alone (case B-1) in place of a fixed cold deck strategy (case A-1) resulted in chilled water energy savings ranging from 7 percent to 11 percent. Considering this strategy as a retrofit option where the ductwork is unchanged, fan energy consumption was reduced by approximately 27 percent. The fan and chilled water energy savings were offset by increased reheat hot water energy consumption, averaging 17 percent for the seven cities.

The results obtained by the above strategy (see discussion in Section 5) were due to reduced supply air quantities in the perimeter zones (sized to satisfy the peak perimeter zone cooling requirement at the lowered cold deck temperature of $12.8^{\circ} \mathrm{C}\left(55^{\circ} \mathrm{F}\right)$ in place of $\left.16.7^{\circ} \mathrm{C}\left(62^{\circ} \mathrm{F}\right)\right)$, as well as the necessity for adding reheat coils to the interior zone to prevent overcooling.

When enthalpy or temperature economy cycles are used, replacing a fixed cold deck strategy (cases $\mathrm{A}-2, \mathrm{~A}-3$ ) with a zone-controlled cold deck strategy (cases $\mathrm{B}-2, \mathrm{~B}-3$ ) results in an average 4 percent increase in chilled water energy consumption. This negative result is probably due to the addition of reheat in the interior zone for the zone-controlled cold deck strategy, resulting in higher cooling loads during the summer months (when the interior zone reheat is expected to operate). Economy cycles during the summer months would not be expected to be effective in reducing the cooling coil load. 
of the strategies investigated for the CV system in the small office building model, the ones which appear to have the clearest impact on overall energy savings are the fixed cold deck with either enthalpy or temperature economy cycles (case $\mathrm{A}-2$ or $\mathrm{A}-3$ ).

In contrast to the mixed results obtained with the CV system, zone-controlled cold deck strategles for the VAV and $\mathrm{CV}-\mathrm{CV}$ systems indicate definite savings in energy consumption. A bar chart is presented in figure $7 a$ for the relative savings in chilled water and hot water energy consumption for the VAV and the $\mathrm{CV}-\mathrm{CV}$ systems when a fixed cold deck temperature strategy (case A-1) is replaced by a zone-controlled cold deck strategy (case B-1). Results for the CV-CV system for Lake Charles or Santa Maria are not shown since their climates would result in uncomfortably high humidities within the building.

As shown in figure $7 \mathrm{a}$, modest savings in chilled water energy consumption ranging from 1 percent to 11 percent are obtained for the VAV system. For the $\mathrm{CV}-\mathrm{CV}$ system, chilled water savings range from 5 percent to 14 percent.

Larger savings in reheat hot water energy consumption are obtained, ranging from 9 percent to 30 percent for the VAV system and from 12 percent to 21 percent for the $\mathrm{CV}-\mathrm{CV}$ system.

Fan energy consumption for the VAV system increases-manging from 1 to 14 percent for the seven cities. As discussed in Section 5, the increase is expected since the supply air damper opening on some zones must increase to meet the zone cooling load at the higher cold deck supply air temperatures. Fan energy consumption for the $\mathrm{CV}-\mathrm{CV}$ system did not change since supply air flowrate remained the same as with the fixed cold deck strategy.

Figure $7 \mathrm{~b}$ is a bar chart for chilled water and hot water energy savings when zone-controlled cold deck is added to the VAV and $\mathrm{CV}-\mathrm{CV}$ systems having preexisting enthalpy economizers (case B-2 versus case A-2). As shown for the CVCV system in figure $7 \mathrm{~b}$, negligible additional savings (approximately 1 percent) in chilled water energy consumption occur when an enthalpy economy cycle is added to a zone-controlled cold deck (case B-2) as compared to one added to a fixed cold deck (case $\mathrm{A}-2$ ). This result is largely due to the fact that a zone-controlled cold deck is effective during the winter months when solar heat gains and outside-air induced heat conduction losses result in low cooling loads. This condition may typically occur at outside air temperatures below $12.8^{\circ} \mathrm{C}\left(55^{\circ} \mathrm{F}\right)$ and it is therefore immaterial whether or not a zone-controlled cold deck (setpoints ranging from $12.8^{\circ} \mathrm{C}\left(55^{\circ} \mathrm{F}\right)$ to $16.7^{\circ} \mathrm{C}\left(62^{\circ} \mathrm{F}\right)$ ) is applied since in this cold deck temperature range the cooling coil is nearly zero.

For the $C V-C V$ system in $f$ igure $7 b$, reheat hot water energy savings from 12 percent to 21 percent are shown and are nearly identical to the savings shown in figure 7a. Nearly equal savings are due to the fact that reheat hot water energy consumption is dependent on the cold deck supply air set point temperature and not on the source for supply air cooling (outside air or cooling coil). 
For the VAV system, the results shown in figure $7 \mathrm{~b}$ indicate additional savings in chilled water energy consumption for the strategy consisting of zonecontrolled cold deck with enthalpy economy cycle (case B-2) versus a fixed cold deck with enthalpy economy cycle (case A-2). In contrast to the CV-CV system, the VAV system can modulate the cooling capacity by resetting the zone supply air dampers. When all zones are experiencing moderate cooling loads the supply air temperature for the $\mathrm{CV}-\mathrm{CV}$ system is fixed at a certain value (ranging from $12.8^{\circ} \mathrm{C}\left(55^{\circ} \mathrm{F}\right)$ to $16.7^{\circ} \mathrm{C}\left(62^{\circ} \mathrm{F}\right)$ ) by the zone with the greatest cooling demand. For the VAV system however, under similar zone loads, the supply air temperature can be reset to a higher value since the zones air dampers will increase the supply air quantity to satisfy the zone cooling loads. The net result is that the VAV system operates at supply air temperatures which are more often higher than in the CV-CV system. By adding an enthalpy economy cycle to the VAV system with zone-controlled cold deck (case B-2) the cooling coil load is further reduced over a fixed cold deck with enthalpy economy cycle (case $\mathrm{A}-2$ ) since there are more hours in which the outdoor temperature is below $16.7^{\circ} \mathrm{C}\left(62^{\circ} \mathrm{F}\right)$ than below $12.8^{\circ} \mathrm{C}\left(55^{\circ} \mathrm{F}\right)$.

The savings in reheat hot water energy consumption for the VAV system are approximately equal to the results shown in figure $7 \mathrm{a}$. The reason for the nearly identical savings is the same as that given for the CV-CV system.

The results obtained for the VAV system and the $\mathrm{CV}-\mathrm{CV}$ system in figure 7 were found to apply as well to zone-controlled cold deck with temperature economy cycle (cases B-2 versus A-3) in place of enthalpy economy cycle (case B-2 versus $A-2)$.

\subsection{EVALUATION OF SYSTEMS AND STRATEGIES}

Analysis of the results obtained with the small office building have led to some general conclusions as to the performance of systems in small office building of different thermophysical design and usage patterns. A more complete discussion of practices and principles in HVAC system design and selection, may be found in the ASHRAE Handbook and Product Directory 6 .

With respect to variable air volume systems, zones of a building which exhibit small fluctuating loads may be well served by systems having a minimum air volume ratio of 0.4 rather than 0.2 . Presumably the former system is cheaper on a first cost bases. Other considerations such as minimum ventilation requirements and maximum outlet air temperatures may dictate the minimum air volume ratio. Cold deck supply air temperatures must also be low enough to permit adequate dehumidification of zones experiencing small sensible cooling loads.

In the following discussion some of the factors to be considered in efficient zoning of two or more systems to a building are outlined. For optimum system performance, a system should control those zones which exhibit similar heating

6 ASHRAE Handbook and Product Directory, 1980 Systems, American Society of Heating, Refrigerating and Air Conditioning Engineers, New York, NY, 1980. 
and cooling load patterns. This can permit effective use of cold deck supply air reset and economy cycles.

When one or more zones must be continuously cooled it may be advisable to dedicate one system to these zones. If these zones exhibit highly fluctuating loads a variable air volume system or induction system may be appropriate. If the loads are nearly constant during the occupied hours but are greatly reduced during unoccupied hours, a constant volume system with intermittent operation during unoccupied periods may be a feasable alternative.

In order to decide which system strategy is most appropriate it is necessary to evaluate the relative energy operating costs of various combinations of systems and strategies. This requires information of the cost of fossile fuels, electricity and the efficiencies of heating plants, chillers and circulating fans. The cost of electricity and fossil fuels will vary by locality. In many cases the type of heating plant, chiller and circulating fans is dictated by the system. This is evident, for instance for variable air volume systems in which the supply fan should exhibit high efficiency at low supply air flow rates. In this same system, the cooling coil may exhibit widely varying loads so that the type of chiller and its part load performance can play a key role in reducing energy costs. 


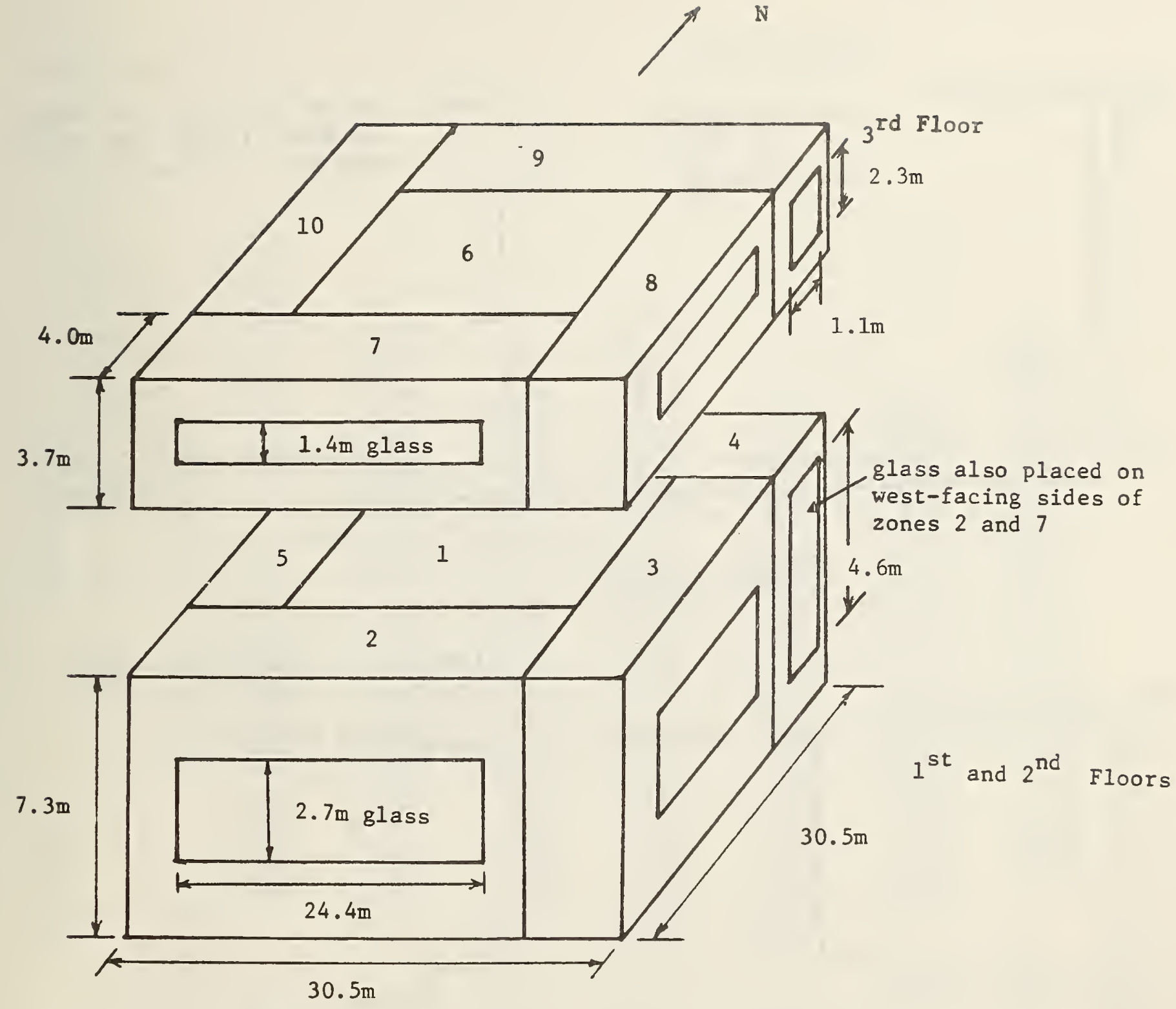

Exterior Walls: Metal Curtain/Airspace/2" Insul./Gypsum Board

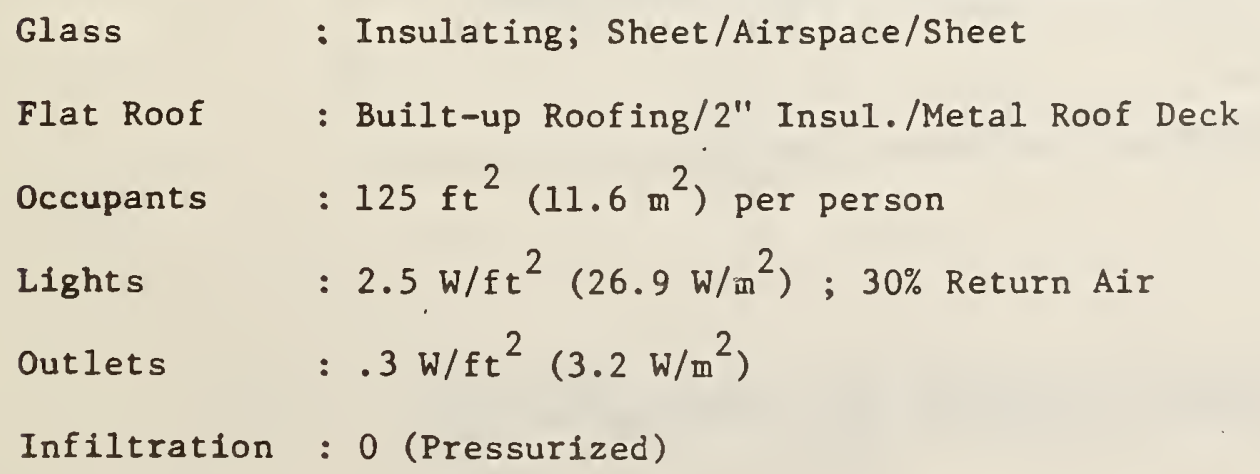

Figure 1 Small office building model 

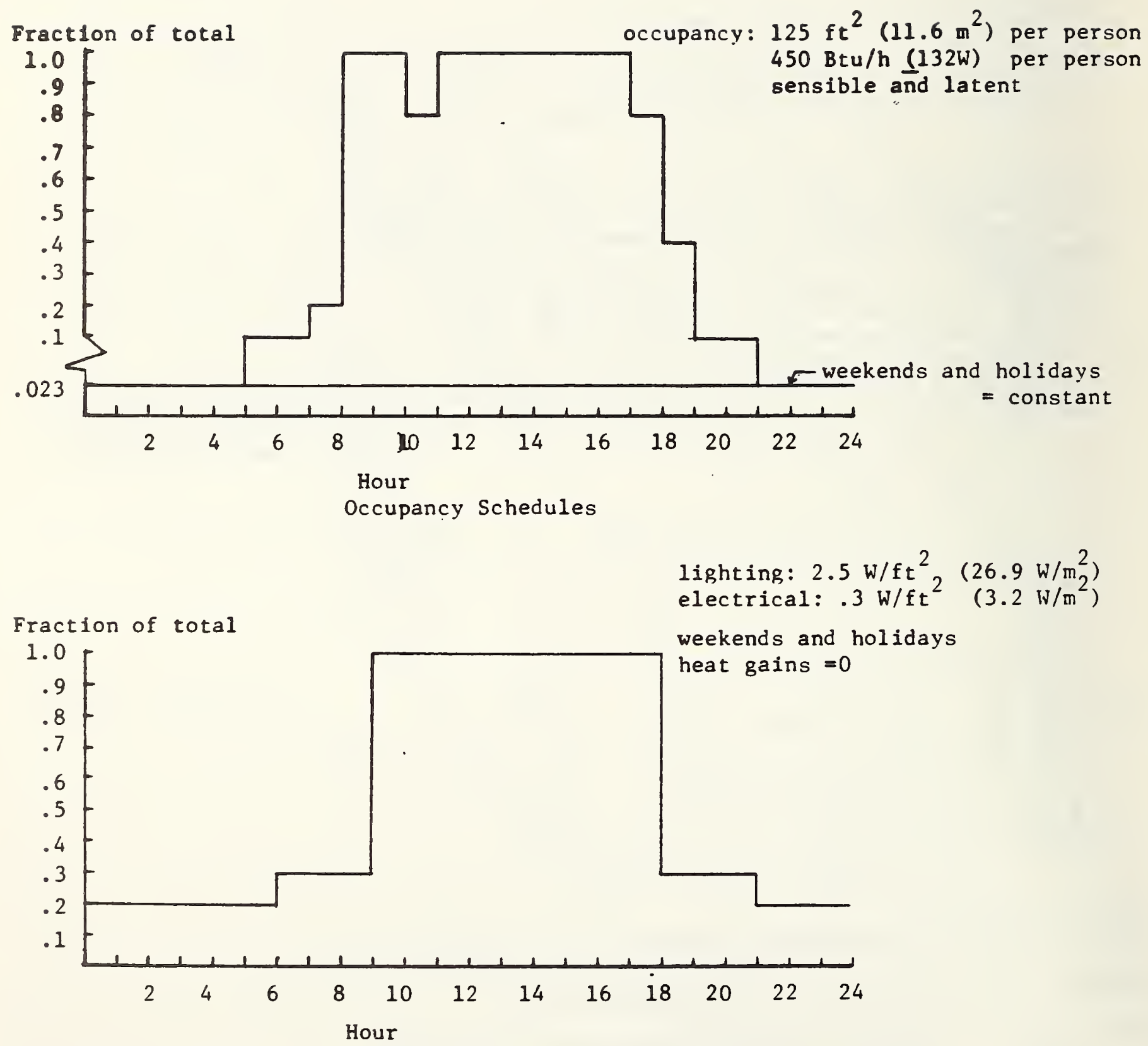

Electrical Appliances and Lighting Schedules

Figure? Internal heat gain schedules 
ENERGY CONSUMPTION,

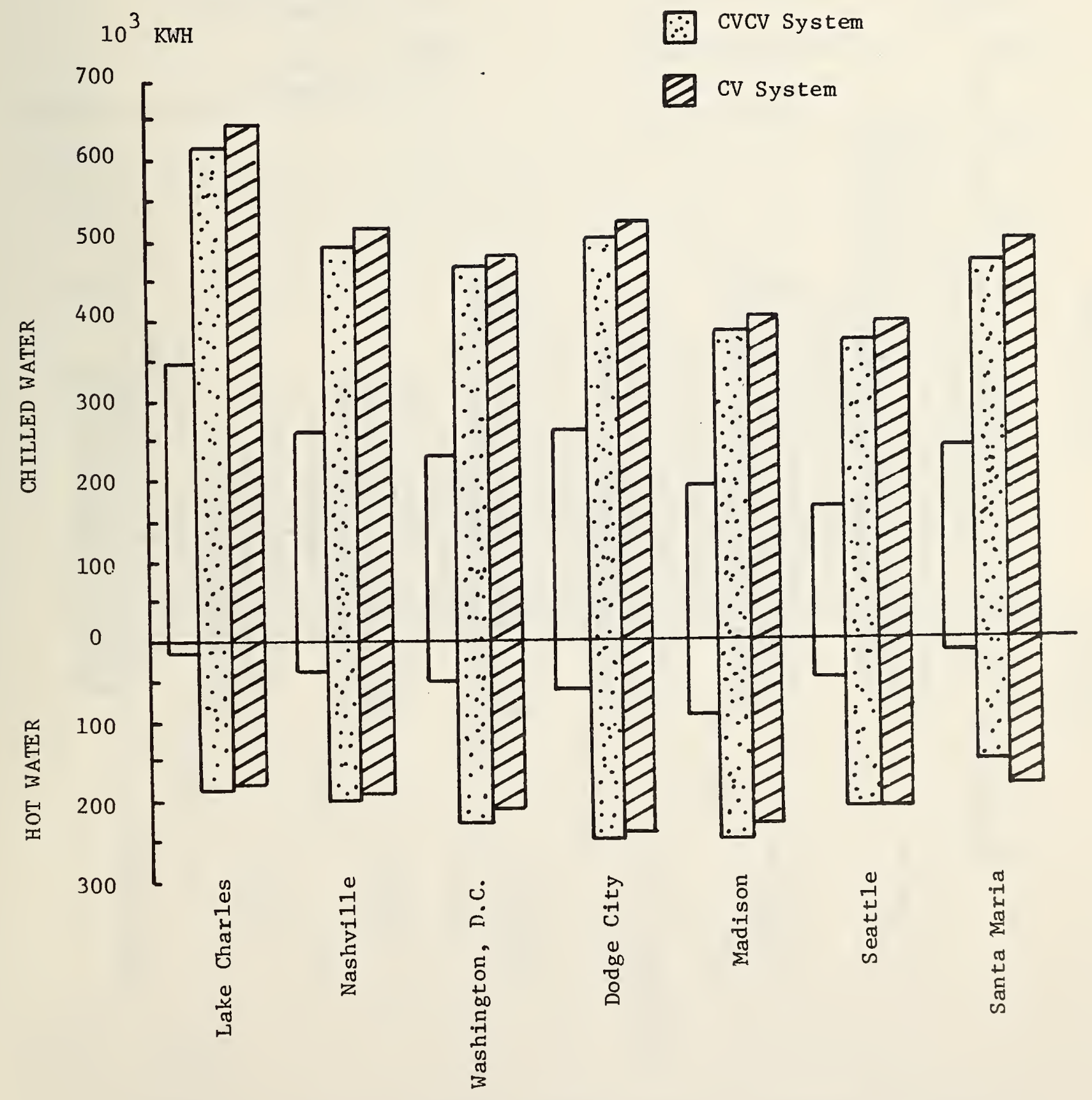

Figure 3 Annual heating and cooling energy consumption of three HVAC systems utilizing the base case strategy ( $A-1)$ for a small office building 
ENERGY CONS UMPTION,

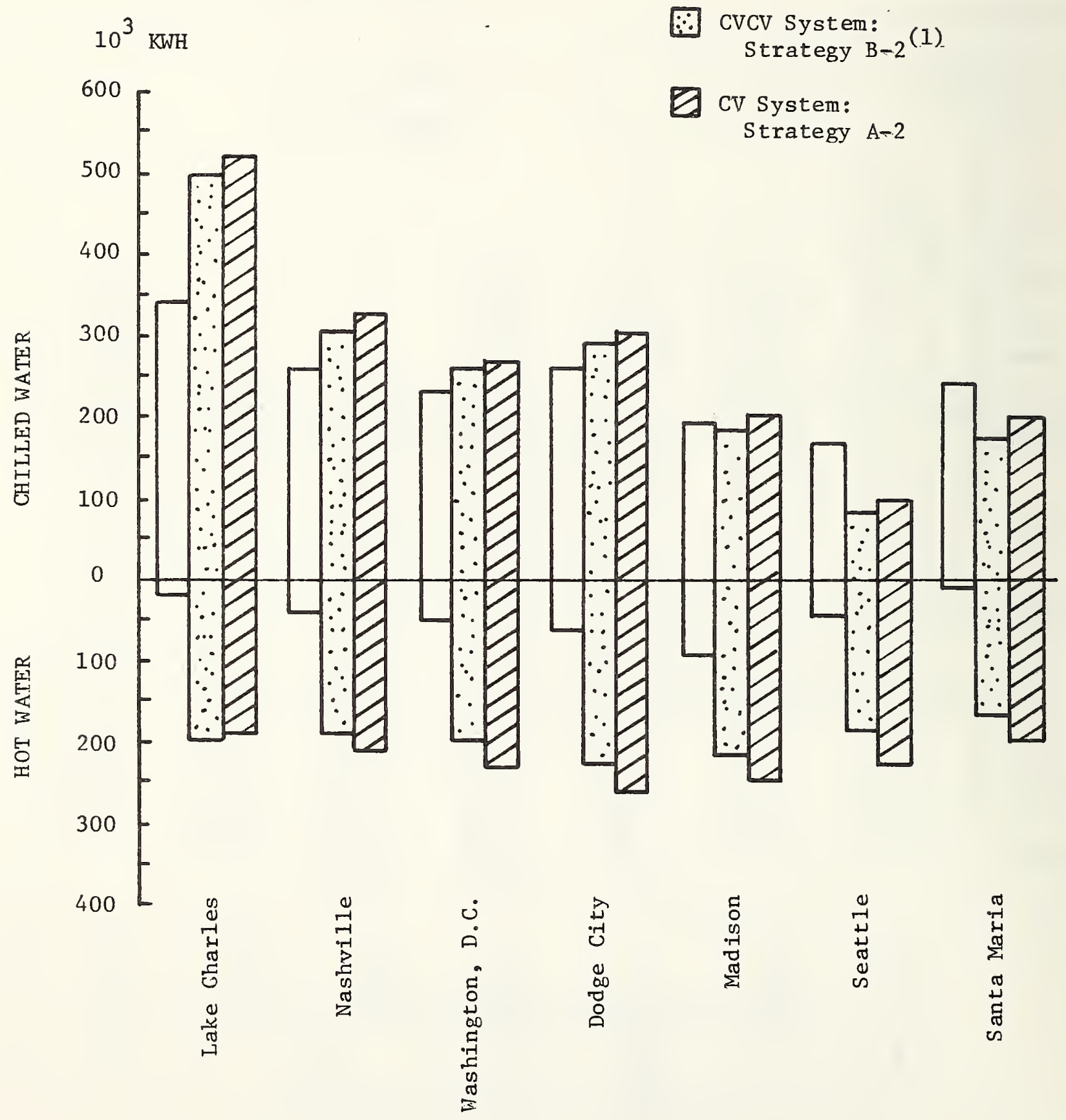

Figure 4 Comparative annual heating and cooling energy consumption for a VAV system using the base case strategy with CV and CV-CV system utilizing their respective best case strategies

(1) Stragegy B-2 not possible to implement for Lake Charles and Santa Maria for this system. 
$\square$ VAV system

CVCV System

PERCENT SAVINGS

CV system

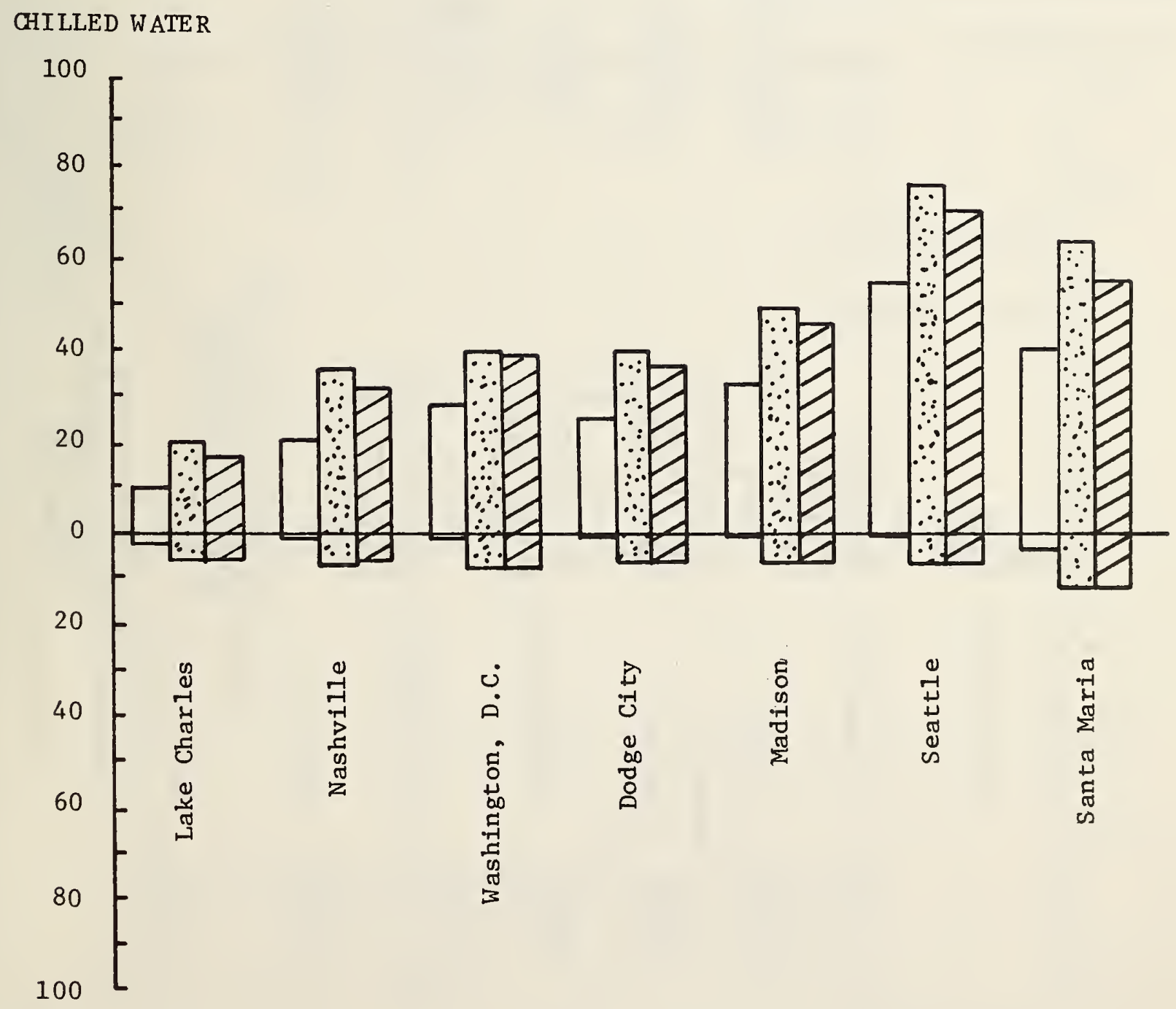

\section{PERCENT INCREASE}

HOT WATER

Figure 5 Percent savings in chilled water and percent increases in hot water energy consumption for three HVAC systems using enthalpy economy cycle*

*Average values for fixed cold deck temperature and zone controlled cold deck temperatures 
DAV System

$\therefore$ CVCV System

PERCENT SAVINGS,

CHILLED WATER

CV System

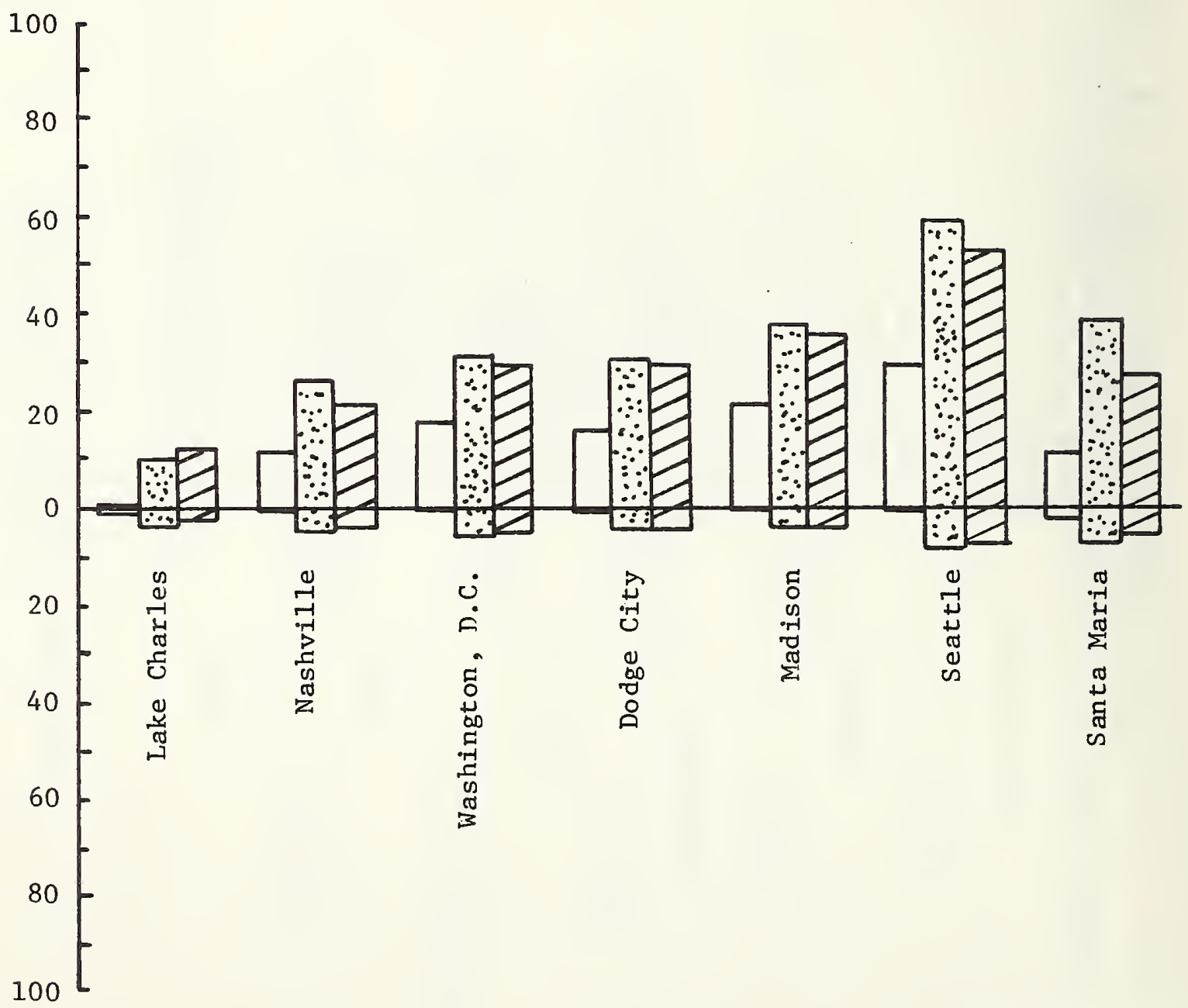

PERCENT INCREASE,

HOT WATER

Figure 6 Percent savings in chilled water and percent increases in hot water energy consumption for three HVAC systems using temperature economy cycle*

*Average values for fixed cold deck temperature and zone-controlled cold deck temperature. 


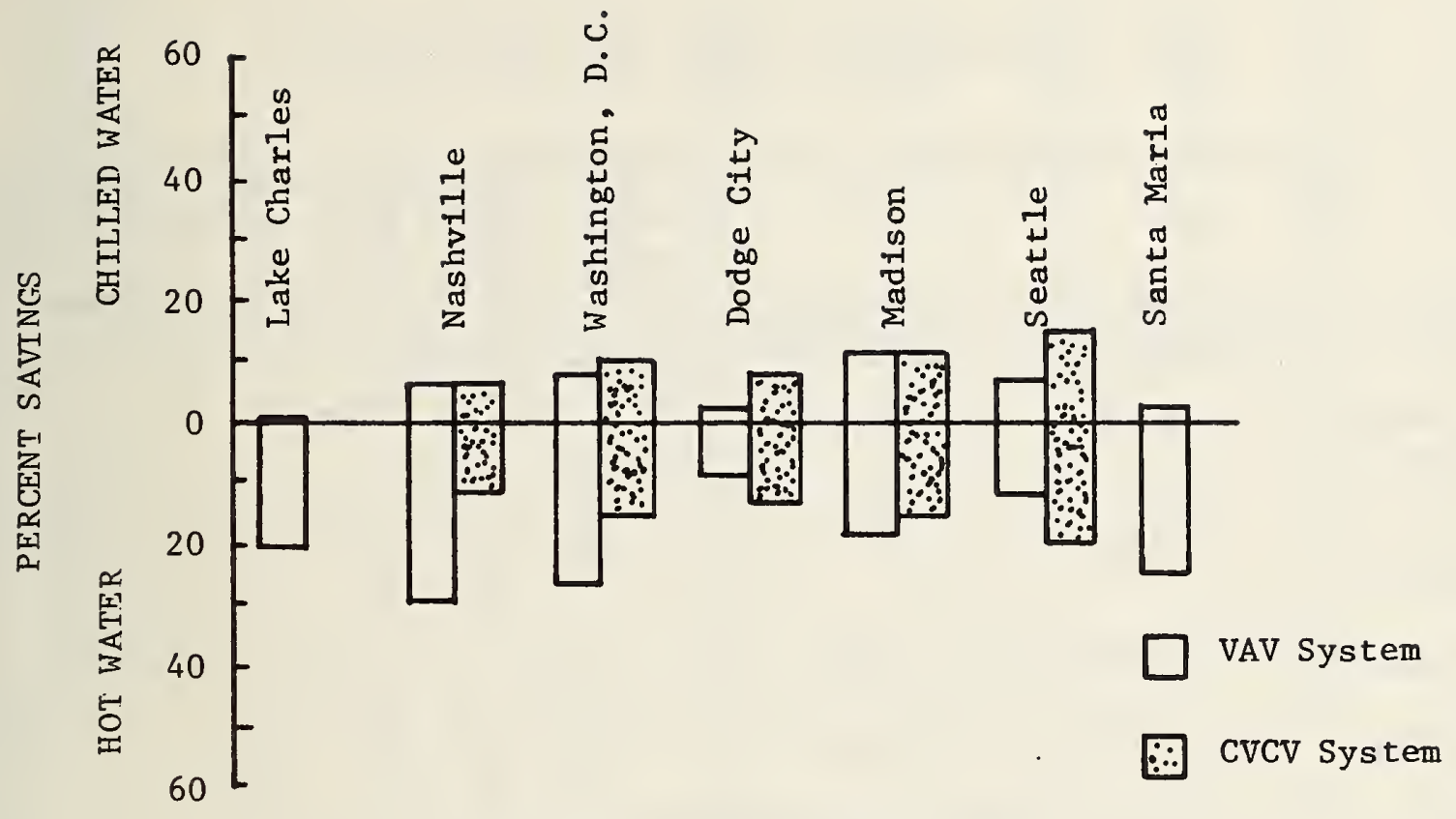

Figure 7a No Economy Cycle

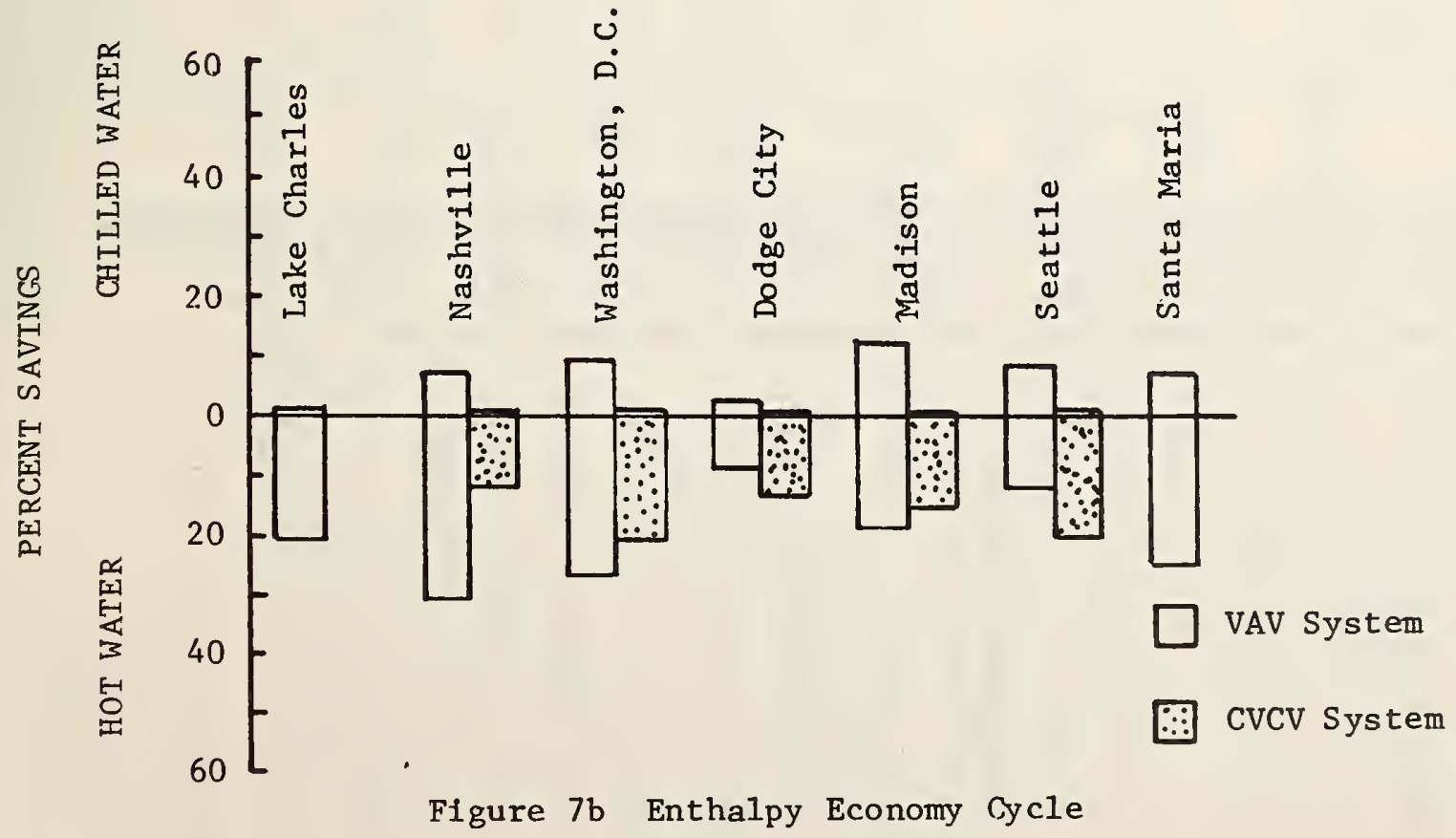

Figure 7 Chilled water and hot water energy savings achieved for strategies employing zone-controlled cold deck as compared to a fixed cold deck temperature 
Table 1. Climatological Data for Seven Cities*

\begin{tabular}{|c|c|c|c|}
\hline City & $\begin{array}{c}\text { Cooling } \\
\text { Degree Days } \\
\end{array}$ & $\begin{array}{c}\text { Heating } \\
\text { Degree Days }\end{array}$ & $\begin{array}{l}\text { The percentage of temperature bin } \\
\text { hours ranging from representative } \\
\text { temperatures of } 13.9^{\circ} \mathrm{C}\left(57^{\circ} \mathrm{F}\right) \text { to } \\
22.2^{\circ} \mathrm{C}\left(72^{\circ} \mathrm{F}\right)-\text { for the daylight } \\
\text { hours from } 9 \mathrm{a} . \mathrm{m} \text {. to } 4 \text { p.m. }\end{array}$ \\
\hline $\begin{array}{l}\text { Lake Charles, } \\
\text { Louisiana }\end{array}$ & 2739 & 1498 & $31 \%$ \\
\hline $\begin{array}{l}\text { Nashville, } \\
\text { Tennessee }\end{array}$ & 1694 & 3696 & $34 \%$ \\
\hline Washington, $\mathrm{DC}$ & 1415 & 4211 & $32 \%$ \\
\hline $\begin{array}{l}\text { Dodge City, } \\
\text { Kansas }\end{array}$ & 1411 & 5046 & $29 \%$ \\
\hline $\begin{array}{l}\text { Madison, } \\
\text { Wisconsin }\end{array}$ & 460 & 7730 & $28 \%$ \\
\hline $\begin{array}{l}\text { Seattle, } \\
\text { Washington }\end{array}$ & 183 & 4727 & $44 \%$ \\
\hline $\begin{array}{l}\text { Santa Maria, } \\
\text { California }\end{array}$ & 84 & 3053 & $82 \%$ \\
\hline
\end{tabular}

* Derived from data supplied by: (1) Engineering Weather Data; Departments of the Air Force, the Army and the Navy; AFM 88-29, July 1978; (2) Local Climatological Data-Annual Summaries for 1975; National Oceanic and Atmospheric Administration, Environmental Data Service, Ashville, N.C. 


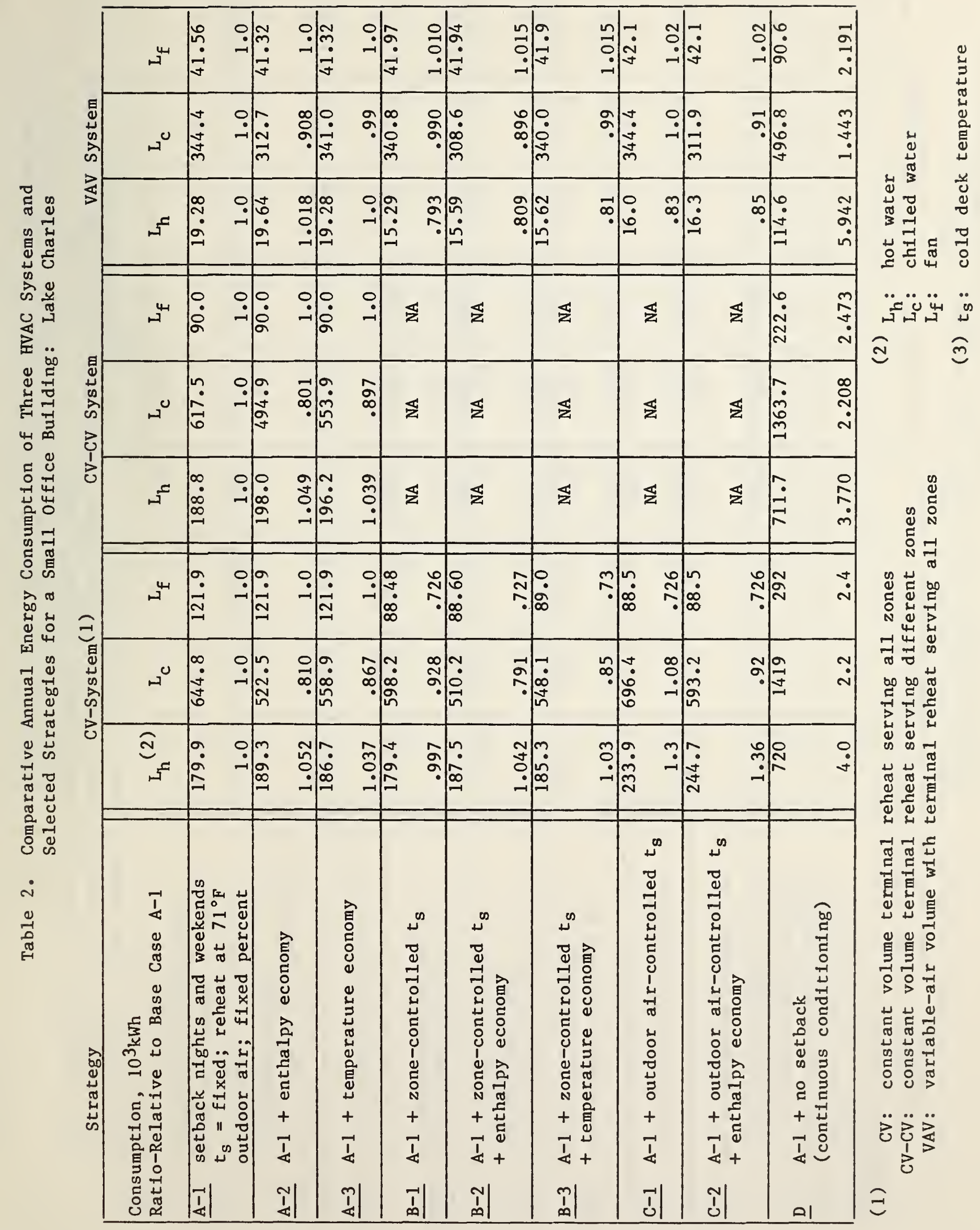




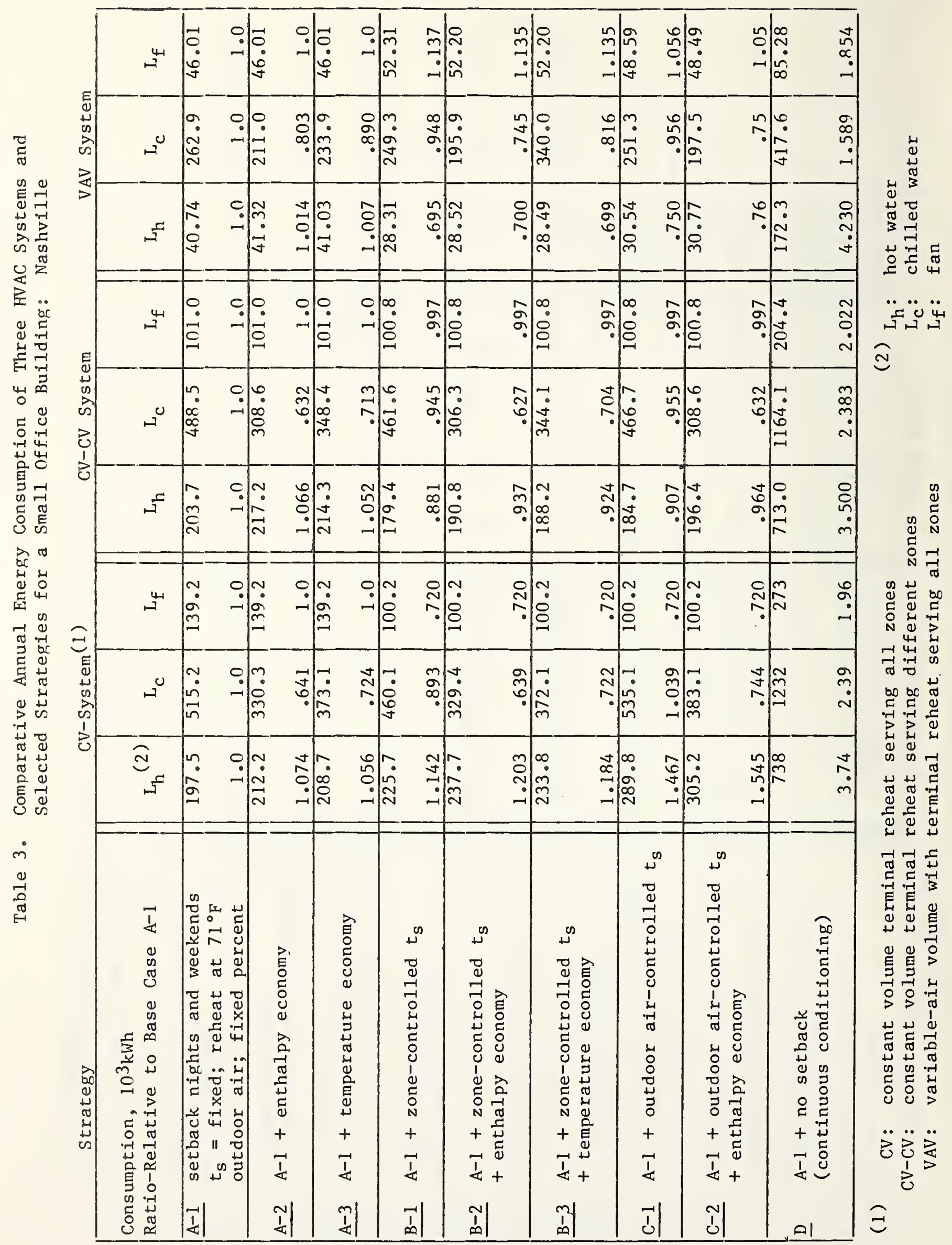




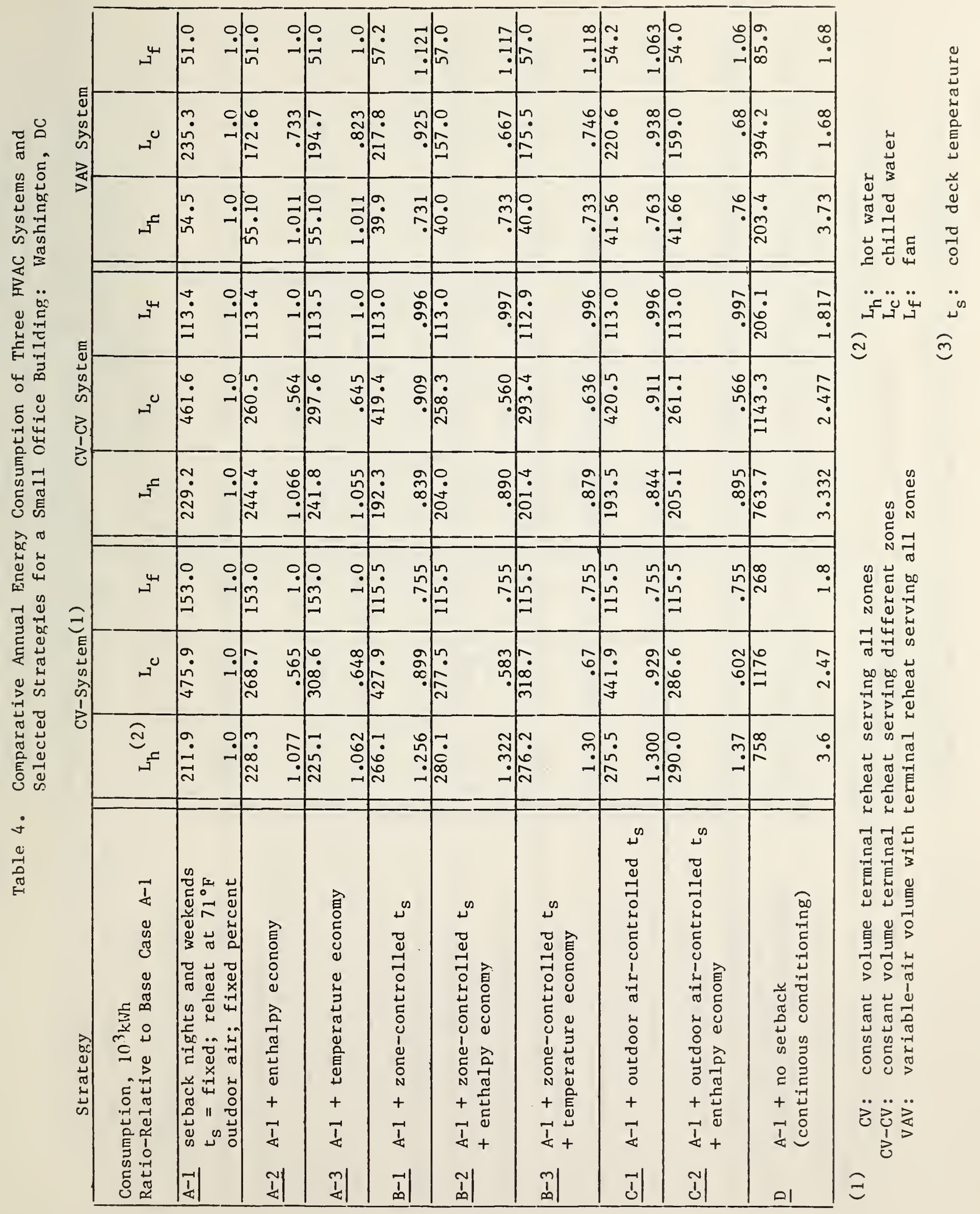




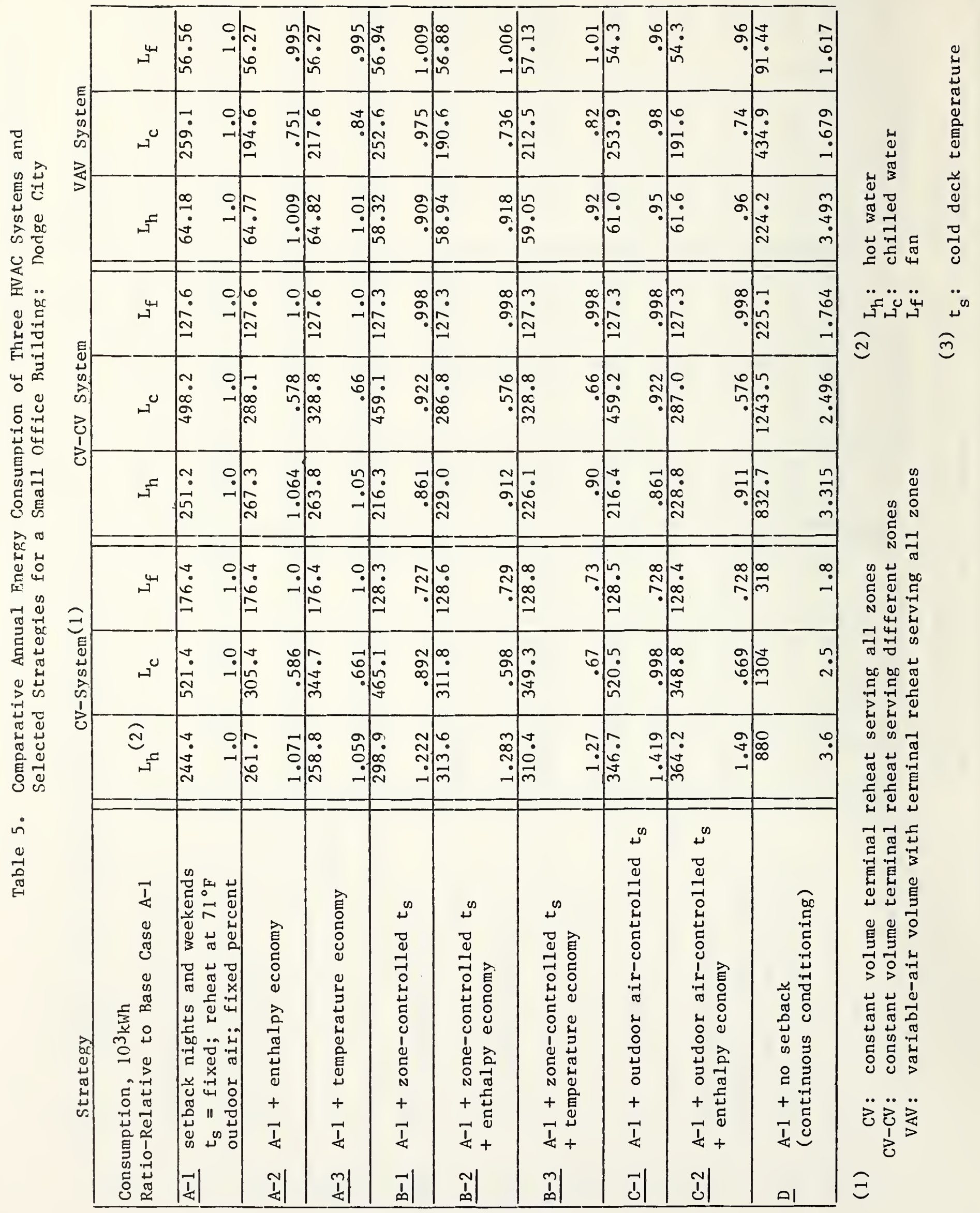




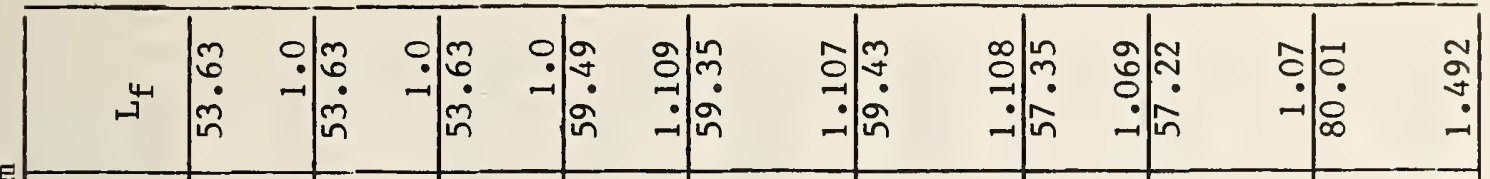

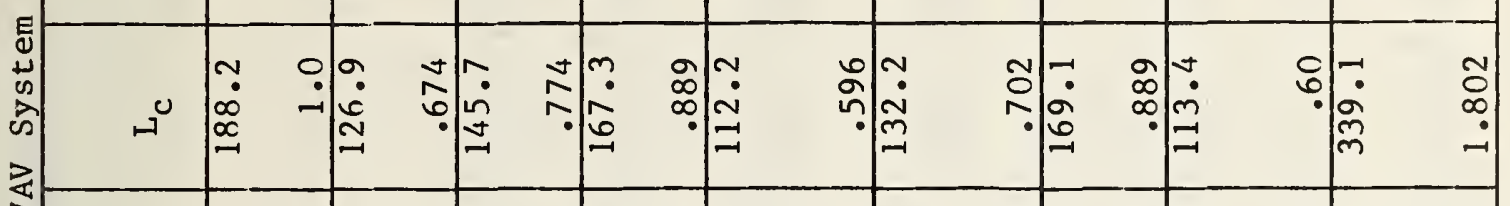

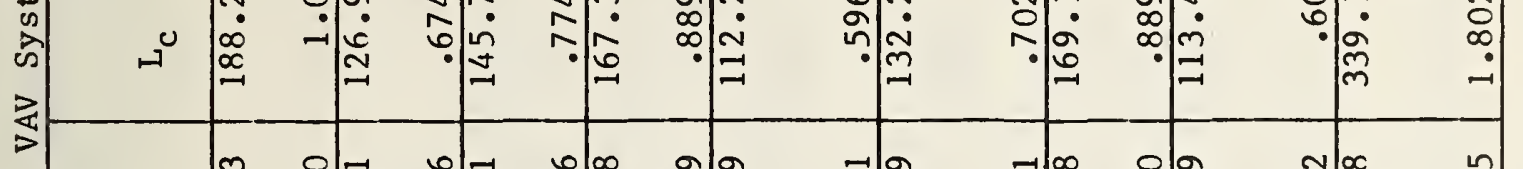

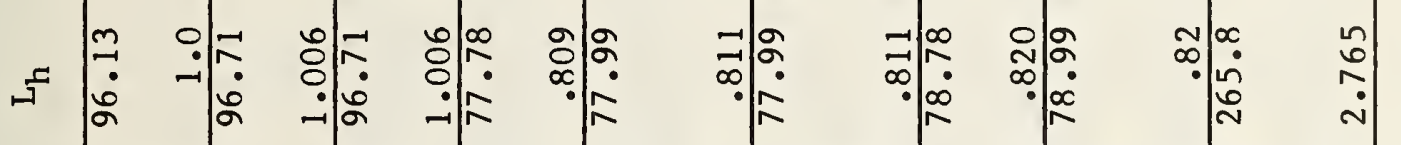

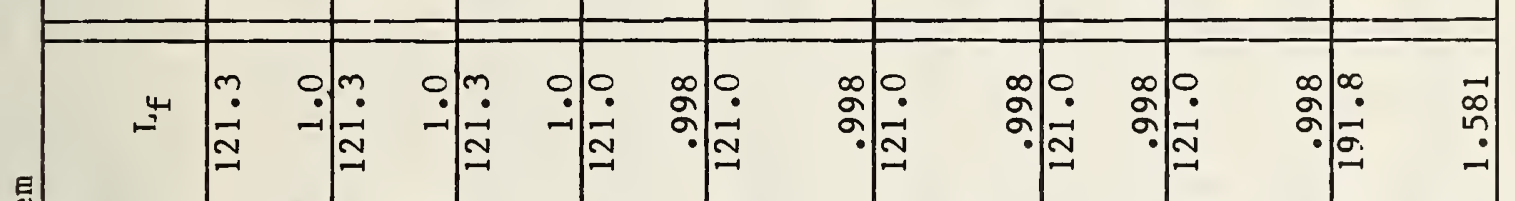

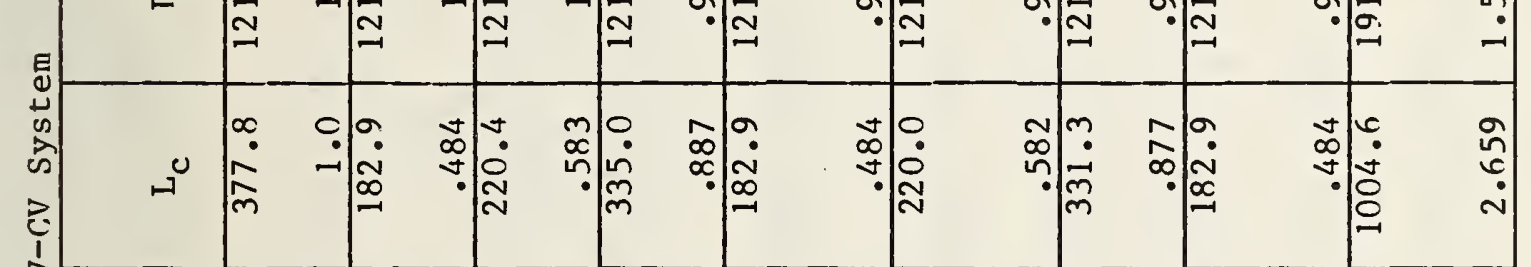
3

㫕

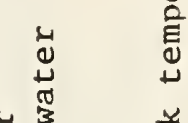

苟先

可苗 的 กิ กิ

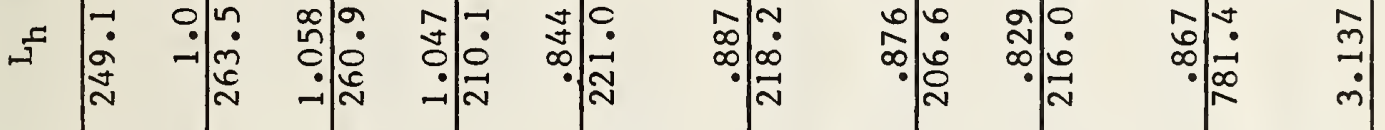

(2) 옹

등-

긍

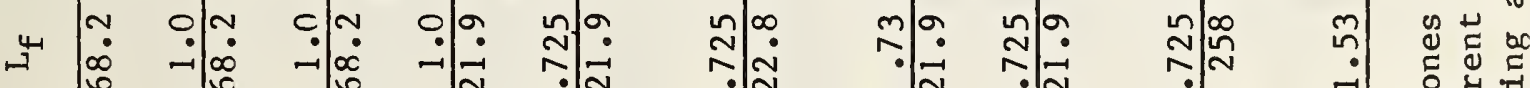

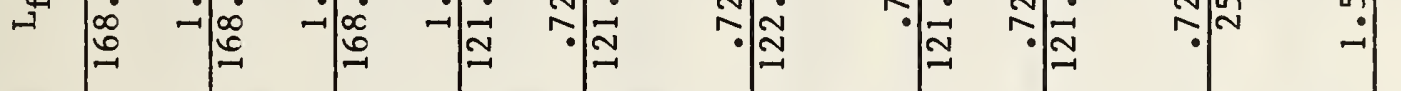

N 3

더건

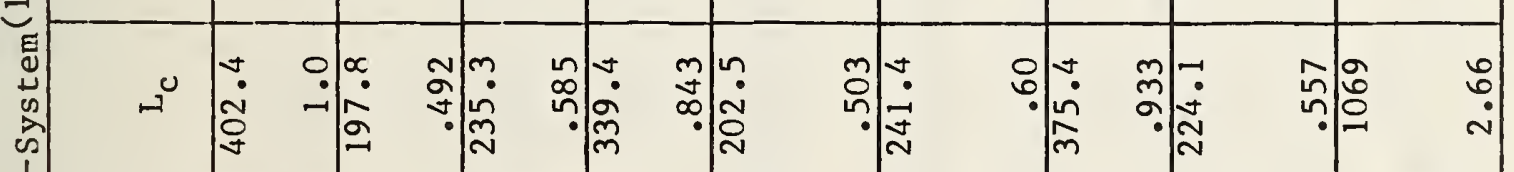

己े

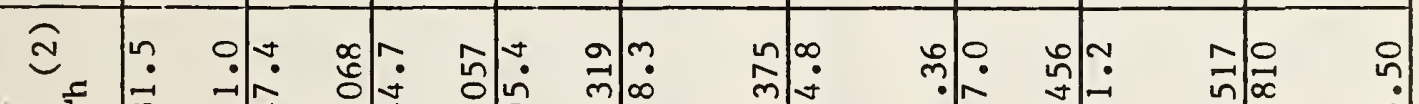

or ac $\stackrel{4}{\pi}$

है

?

() ब

का का

㫕

\&

वे क्ष

\begin{tabular}{|c|c|c|c|c|c|c|c|c|c|}
\hline 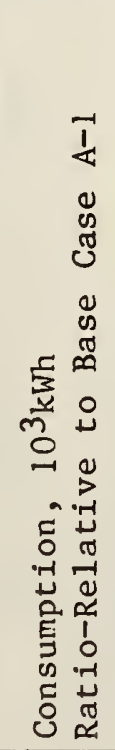 & 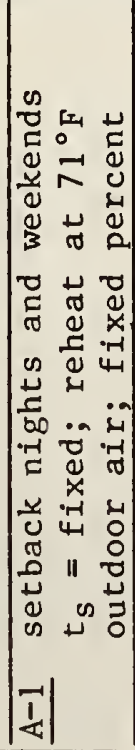 & 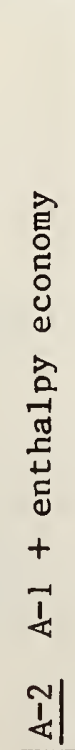 & 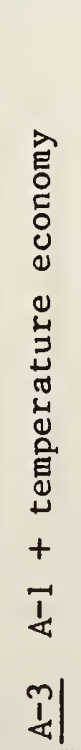 & 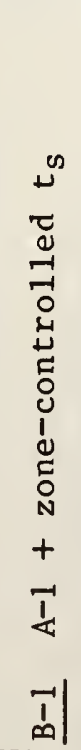 & 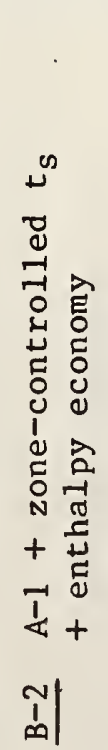 & 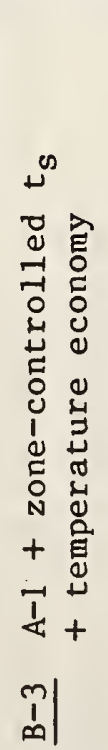 & 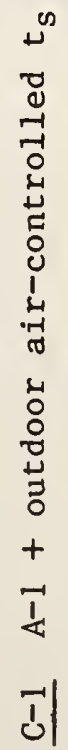 & 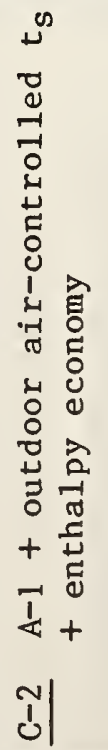 & 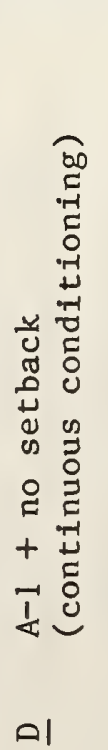 \\
\hline
\end{tabular}




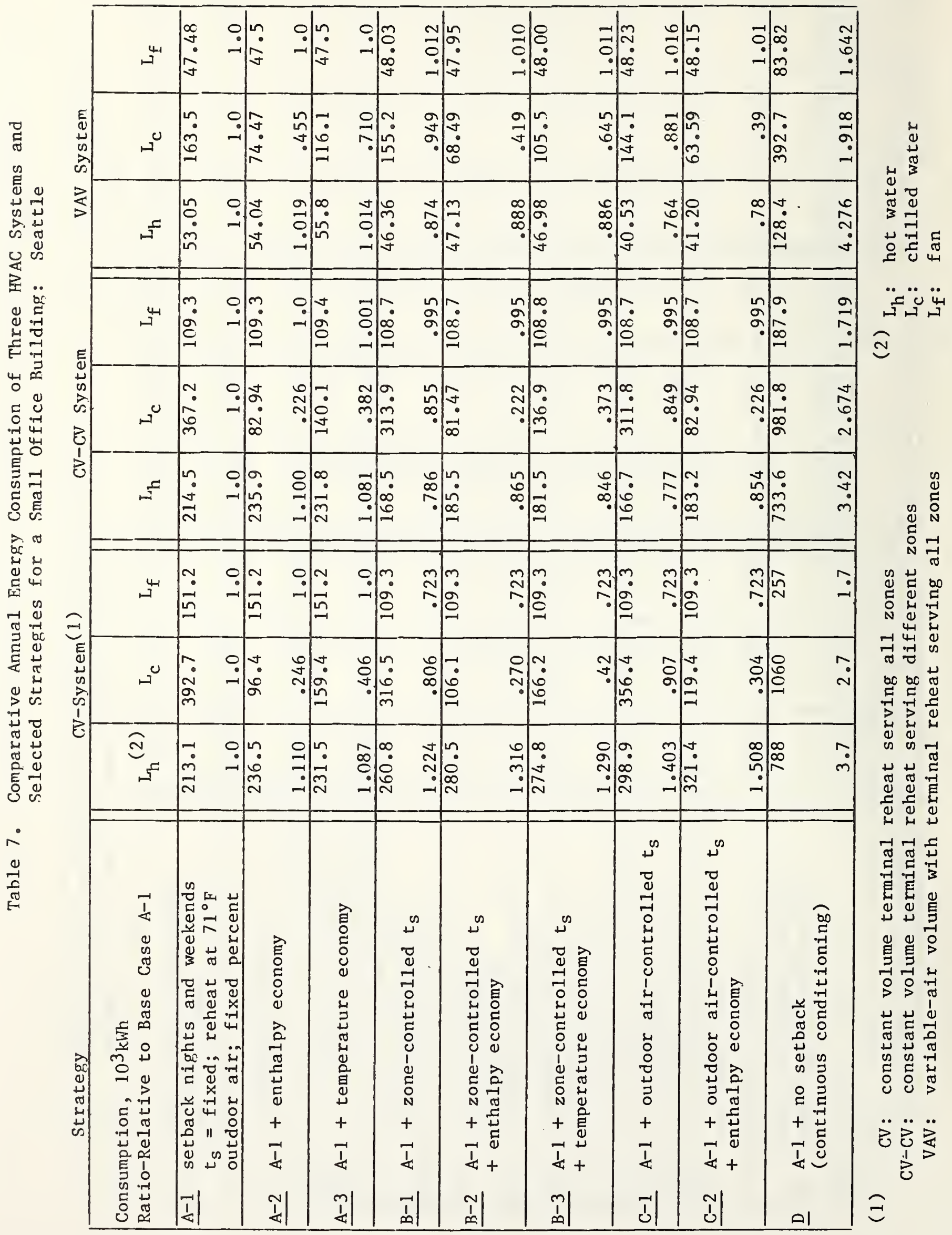




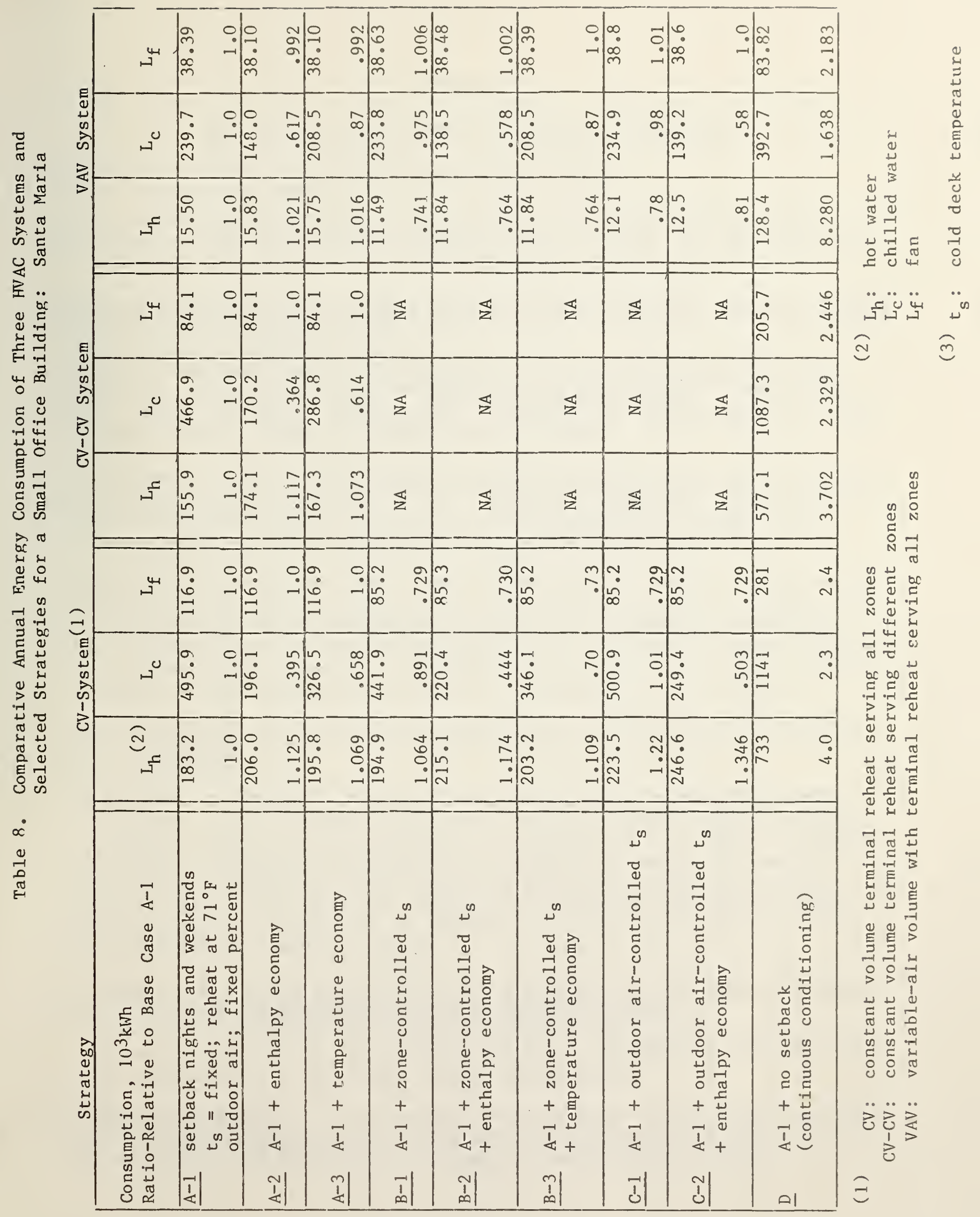



APPENDIX A

RESULTS FROM SIMULATIONS OF ADDITIONAL STRATEGIES

Comparison of Additional Strategies for the CV System

Several additional strategies were simulated for the CV system in order to determine the effects on energy consumption for hot water, chilled water and fan energy.

Base Case Strategy (case A-1) and Base Case Strategy with Cold Deck Temperature of $55^{\circ} \mathrm{F}\left(12.8^{\circ} \mathrm{C}\right)($ cases $\mathrm{F}-1, \mathrm{~F}-2)$

The results were obtained for Washington, DC weather only to illustrate the effects of reducing the cold deck temperature from $16.7^{\circ} \mathrm{C}\left(62^{\circ} \mathrm{F}\right)$ to $12.8^{\circ} \mathrm{C}$ $\left(55^{\circ} \mathrm{F}\right.$ ) (cases $\mathrm{A}-1$ and $\mathrm{F}-1$ respectively). Strategy $\mathrm{F}-2$ is similar to strategy F-1 except that an enthaply economy cycle is added.

For strategy $\mathrm{F}-1$ the hot water energy consumption increases by 12 percent and chilled water consumption increases by 4 percent over the base case. Due to lower air flow rates required at a $12.8^{\circ} \mathrm{C}\left(55^{\circ} \mathrm{F}\right)$ supply air temperature, a reduction in fan energy of approximately 31 percent is observed.

Incorporating an enthalpy economy cycle to strategy $\mathrm{F}-1$ (case F-2) results in an increase in hot water energy consumption of 19 percent over the base case, and identical fan energy consumption as in case F-1. Reduction in chilled water energy consumption over the base case is 34 percent. It should be noted, however, that larger savings are obtained by employing a $16.7^{\circ} \mathrm{C}\left(62^{\circ} \mathrm{F}\right) \operatorname{col} \mathrm{d}$ deck with enthalpy economy cycle (case B-2) and amounts to 44 percent.

Effect of Reducing the Cold Deck Throttling Range from $1.7^{\circ} \mathrm{C}\left(3^{\circ} \mathrm{F}\right)$ to $0.28^{\circ} \mathrm{C}$ $\left(0.5^{\circ} \mathrm{F}\right)($ case $\mathrm{H}-1)$

Strategy $\mathrm{H}-1$ was similar to the base case strategy with an enthalpy economy cycle added (case A-2) except that $0.28^{\circ} \mathrm{C}\left(0.5^{\circ} \mathrm{F}\right)$ cold deck throttling range was simulated. This case was simulated for Washington, DC weather. Although such a small throttling range may be impractical, the results are used to illustrate the sensitivity of hot water and chilled water energy consumption to throttling range. As compared to strategy A-2 hot water and chilled water energy consumption decreases by 29 percent and 14 percent respectively - fan energy consumption remains the same.

Comparison of the Base Case Strategy to One Employing a Cold Deck Temperature of $12.8^{\circ} \mathrm{C}\left(55^{\circ} \mathrm{F}\right)$ and Reheating at $25.6^{\circ} \mathrm{C}\left(78^{\circ} \mathrm{F}\right)$ (case $\left.\mathrm{E}-1\right)$

It is evident strategy $\mathrm{E}-1$ is extremely wasteful, the extent in increases in energy consumption over the base case are listed helow.

Fan Energy Consumption: Due to reduced air flow rates required when operating with a cold deck temperature of $12.8^{\circ} \mathrm{C}\left(55^{\circ} \mathrm{F}\right)$ decreases in fan energy over the base case range from 30 percent to 33 percent for all seven cities. 
Hot Water Energy Consumption: Increases in hot water energy consumption over the base case strategy range from 60 percent to 80 percent, decreasing with a decrease in the number of cooling degree days for all seven cities.

Chilled Water Energy Consumption: Increases in chilled water consumption over the base case range from 15 percent to 21 percent for all seven cities.

Comparison of a VAV System with a Minimum Air Volume Ratio of 0.4 (cases G-1 and $(\mathrm{G}-2)$ with the Base Case Strategy $(\mathrm{A}-1)$

Simulations were conducted for the VAV system for a minimum air fraction of 0.4 with an enthalpy economy cycle (case G-2) and without an enthalpy economy cycle (case G-1). In all other respects the strategies for this system are the same as the base case strategy (case A-1). Energy consumption estimates were made for several cities based on correlation obtained from the results of the remaining cities and are presented in table $\mathrm{A}-1$.

Fan Energy Consumption. Increases in fan energy consumption for strategies G-1 (without enthalpy economy) and G-2 (with enthalpy economy) over the base case strategy (case A-1) range from 8 percent to 10 percent for six cities, and approximately 13 percent for Dodge City. As observed in previous results negligible differences in fan energy consumption result when adding enthalpy economy cycles (case G-2).

Hot Water Energy Consumption. The following table lists the percent increases in hot water energy consumption required for reheat for strategy G-1 compared to the base case strategy $(\mathrm{A}-1)$. The second row compares the base case strategy A-1 for the VAV system with the corresponding base case strategy (A-1) for the CV system.

Percent

Lake Washington

Santa Increase Charles Nashville DC Dodge Madison Seattle Maria

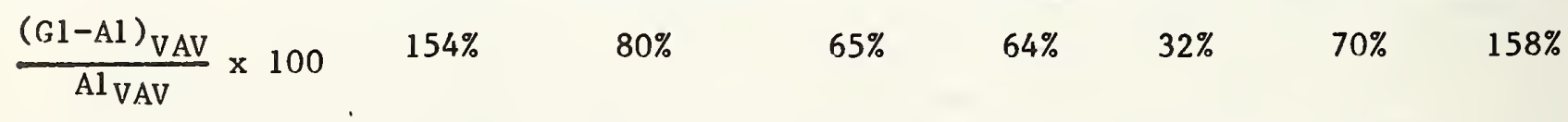

$\frac{\left(\mathrm{Al}_{\mathrm{CV}}-\mathrm{Al} \mathrm{VAV}\right.}{\left.\mathrm{Al}_{\mathrm{VAV}}\right)} \times 100 \quad 833 \% \quad 384 \% \quad 288 \% \quad 288 \% \quad 141 \% \quad 302 \% \quad 1082 \%$

The above table indicates that the increases in hot water energy consumption of strategy G-1 with respect to Al for the VAV system follow the same trend with cities as the increases in base strategy $\mathrm{A}-1$ for the $\mathrm{CV}$ system with respect to the base case in the CV system. This is expected since as the extent of maximum damper air closure decreases, the system approaches a constant volume system.

Adding an enthalpy economy cycle to strategy G-1 (case G-2) results in a 3 to 8 percent increase in hot water energy consumption. The percent increases in hot water energy consumption generally decrease with a decrease in the number of 
cooling degree days except for Seattle and Santa Maria. It is evident that other factors influence the increase in hot water. As discussed previously, these factors can include the daily outdoor temperatures extremes as well as the mean daily temperature for each season of the year, the length of seasons and the amount of solar radiation.

Chilled Water Energy Consumption. The chilled water energy consumption increases for strategy G-1 (without enthalpy economy cycle) and strategy G-2 (with enthalpy economy cycle) with respect to case A-1 are listed below for the seven cities.

\begin{tabular}{lccccccc}
$\begin{array}{l}\text { Percent } \\
\text { Increase }\end{array}$ & $\begin{array}{c}\text { Lake } \\
\text { Charles }\end{array}$ & Nashville & $\begin{array}{c}\text { Washington } \\
\text { DC }\end{array}$ & Dodge & Madison & Seattle & $\begin{array}{r}\text { Santa } \\
\text { Maria }\end{array}$ \\
\hline Case G-1 & $18 \%$ & $17 \%$ & $20 \%$ & $19 \%$ & $22 \%$ & $32 \%$ & $16 \%$ \\
\hline Case G-2 & $4 \%$ & $-12 \%$ & $-19 \%$ & $-17 \%$ & $-20 \%$ & $-50 \%$ & $-37 \%$
\end{tabular}

The percent increases in strategy (G-1) (without enthalpy economy cycle) as compared to strategy A-1 range from 16 percent to 32 percent for the seven cities. For case G-2, Lake Charles still indicates higher chilled water energy consumption than base case A-1 (without enthalpy economy). It is evident for this city, outdoor temperatures are not low enough or prolonged to result in decreases in chilled water consumption. The remaining cities, however, indicate significant decreases in chilled water consumption, the largest increases occurring for Seattle and Santa Maria. The primary reason for the large decreases exhibited in these cities has been discussed previously. It should be noted, however, that chilled water savings are greater for all cities for strategy A-2 (enthalpy economy and minimum air volume ratio of 0.2 ) than for strategy $G-2$. 


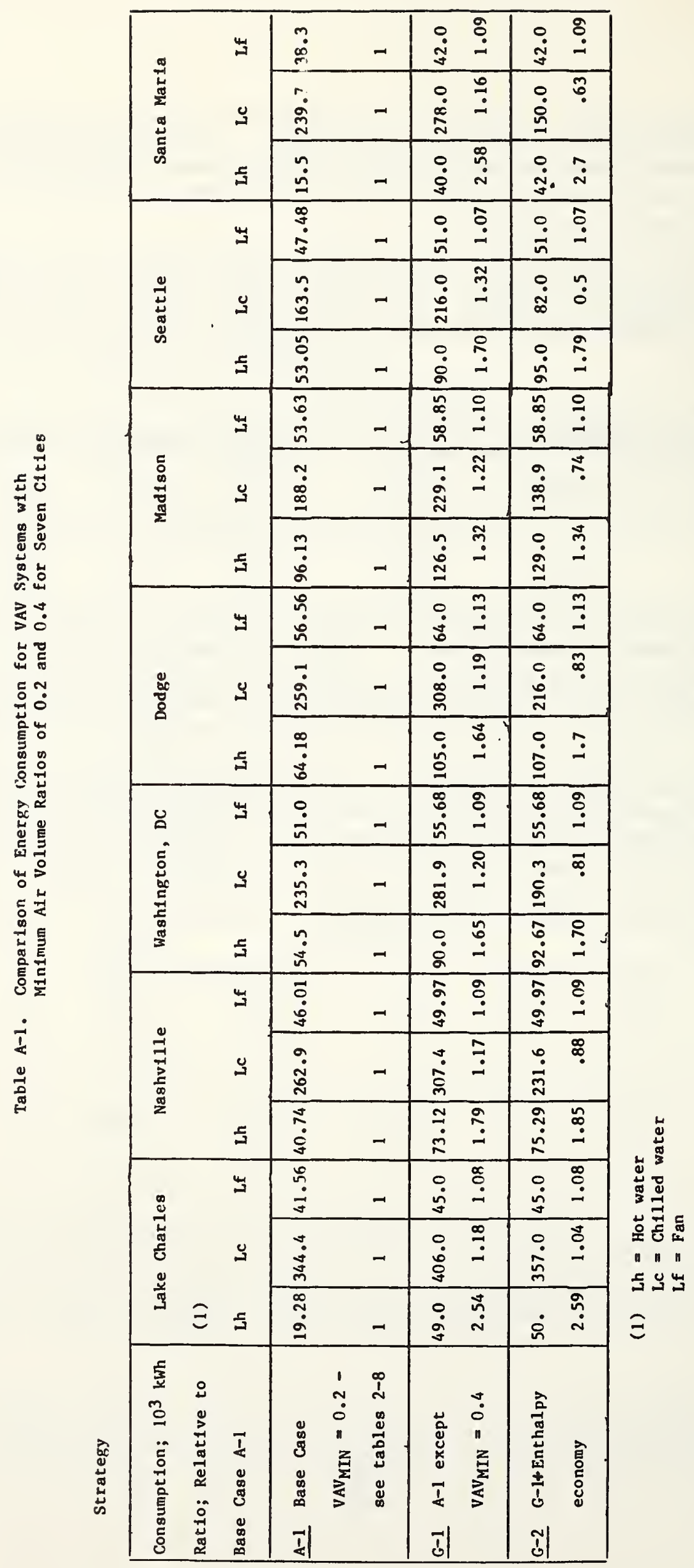


NBS-114A (REV. 2-80)

U.S. DEPT. OF COMM.

1. PUBLICATION OR

2. Performlng Organ. Report No. 3. Publlcation Date

BIBLIOGRAPHIC DATA

REPORT NO.

SHEET (See instructions)

NBSIR 82-2489

July 1982

4. TITLE AND SUBTITLE

Strategies for Energy Conservation in Small Office Buildings

5. AUTHOR(S)

Walter H. Parken, James Y. Kao, George E. Kelly

6. PERFORMING ORGANIZATION (If joint or other than NBS, see instructions)

NATIONAL BUREAU OF STANDARDS

DEPARTMENT OF COMMERCE

WASHINGTON, D.C. 20234

9. SPONSORING ORGANIZATION NAME AND COMPLETE ADDRESS (Street, City, Stote, ZIP)

Office of Buildings Energy Research and Development

Office of Conservation and Renewable Energy

U.S. Department of Energy

Washington, D.C. 20585

10. SUPPLEMENTARY NOTES

Document describes a computer program; SF-185, FIPS Software Summary, is attached.

11. ABSTRACT (A 200-word or less factual summary of most significant information. If document includes a significant bibliogrophy or literoture survey, mention it here)

A comparative analysis is made of the thermal performance of a small office building using various HVAC systems and commonly employed strategies. The comparisons are made for seven geographical locations representing wide climatic variations within the contif nenta1 United States.

Results were obtained for fan, space heating hot water, and chilled water energy consumption through hour-by-hour simulations using the BLAST computer program. A small office building model was used in the simulations along with several HVAC systems; a constant volume reheat unit (serving the entire building), dual constant volume reheat units (serving separate zones of the building), and a variable air volume reheat unit. The strategies investigated included supply air temperature reset (constant, zonecontrolled, and outdoor air-controlled), economy cycles (temperature and enthalpy), continuous conditioning versus conditioning only during occupied hours, changes in reheat set point temperature, and changes in minimum variable air volume ratio.

For comparable control strategies, the variable-air volume terminal reheat system exhibited the least energy consumption for chilled water, hot water and circulating fan. The system incorporating two independently-operating constant volume terminal reheat units ranked second in energy consumption while the single constant volume terminal reheat unit ranked last. Changes in thermal performance resulting from implementing one strategy in place of or in combination with another were found to vary significantly by climate and the type of HVAC system employed.

12. KEY WORDS (Six to twelve entries; alphobetical order: capitalize only proper nomes; and seporate key words by semicolons)

Building control strategies; building energy conservation; building thermal performance HVAC

13. AVAILABILITY

QX Unlimited

For Official Distribution. Do Not Release to NTIS

Order From Superintendent of Documents, U.S. Government Printing Office, Washington, D.C. 20402.

14. NO. OF

PRINTED PAGES

55

15. Price

Order From National Technical Information Service (NTIS), Springfield, VA. 2216I

$\$ 9.00$ 


